\title{
The role of grammatical category information in spoken word retrieval
}

\author{
Carolina Palma Duràn and Agnesa Pillon* \\ Université catholique de Louvain, Louvain-la-Neuve, and Fonds National de la Recherche Scientifique, Belgium
}

\section{Edited by:}

Bradford Mahon, University of

Rochester, USA

\section{Reviewed by:}

Niels Janssen, Universidad de La

Laguna, Spain

Tatiana Schnur, Rice University, USA

*Correspondence:

Agnesa Pillon, Institut de recherche

en sciences psychologiques,

Université catholique de Louvain,

place du Cardinal Mercier, 10, B-1348

Louvain-la-Neuve, Belgium.

e-mail:agnesa.pillon@uclouvain.be
We investigated the role of lexical syntactic information such as grammatical gender and category in spoken word retrieval processes by using a blocking paradigm in picture and written word naming experiments. In Experiments 1, 3, and 4, we found that the naming of target words (nouns) from pictures or written words was faster when these target words were named within a list where only words from the same grammatical category had to be produced (homogeneous category list: all nouns) than when they had to be produced within a list comprising also words from another grammatical category (heterogeneous category list: nouns and verbs). On the other hand, we detected no significant facilitation effect when the target words had to be named within a homogeneous gender list (all masculine nouns) compared to a heterogeneous gender list (both masculine and feminine nouns). In Experiment 2, using the same blocking paradigm by manipulating the semantic category of the items, we found that naming latencies were significantly slower in the semantic category homogeneous in comparison with the semantic category heterogeneous condition. Thus semantic category homogeneity caused an interference, not a facilitation effect like grammatical category homogeneity. Finally, in Experiment 5, nouns in the heterogeneous category condition had to be named just after a verb (category-switching position) or a noun (same-category position). We found a facilitation effect of category homogeneity but no significant effect of position, which showed that the effect of category homogeneity found in Experiments 1, 3, and 4 was not due to a cost of switching between grammatical categories in the heterogeneous grammatical category list. These findings supported the hypothesis that grammatical category information impacts word retrieval processes in speech production, even when words are to be produced in isolation. They are discussed within the context of extant theories of lexical production.

Keywords: speech production, word retrieval, grammatical category, word class, gender, picture naming, word naming

\section{INTRODUCTION}

Lexical knowledge required for the appropriate use of words in connected speech includes knowledge of the words' semantic, syntactic, and phonological properties. In current theories of representation and access to lexical knowledge in speech production (e.g., Roelofs, 1992; Caramazza, 1997; Levelt et al., 1999), it is assumed that these three aspects of lexical knowledge are represented at three independent levels within the word production system and accessed in two steps: first, a lexical unit, corresponding to a lexical node within a network model, is activated on the basis of the semantic properties of the target word; then, the lexical node spreads its activation independently to phoneme nodes, on the one hand, and to syntactic nodes, on the other hand, thus allowing the independent retrieval of the word's phonological content and syntactic features such as grammatical category and gender, respectively. Once retrieved, the word's syntactic features act as constraints for phrase and sentence planning processes. Thus, grammatical category information determines the appropriate syntactic environment for the word, and gender information, the appropriate form of other lexical units like determiners and adjectives in gender-sensitive languages ${ }^{1}$. Moreover, a central assumption of these theories, which is the focus of this study, is that the successful retrieval of a word does not depend on the prior access to its syntactic features ${ }^{2}$ nor could it be influenced in any

\footnotetext{
${ }^{1}$ Beyond these common assumptions, the theories differ on a number of points. For example, in Caramazza's (1997) model, the lexical nodes, called "lexemes," are viewed as modality-specific lexical units while, in Levelt et al.'s (1999), the lexical nodes, called "lemmas," are modality-neutral lexical units. Activation between lexical and phoneme nodes is cascading in Caramazza (1997) and strictly serial in Levelt et al. (1999). These points are, however, not relevant for the purpose of this study. ${ }^{2}$ In the literature, Levelt and collaborators' theory is sometimes described as assuming that the retrieval of a word's syntactic features (e.g., its gender) is necessary for the retrieval of the word form (i.e., the "lexeme" or "morpheme" node). Actually, it is in those terms that Caramazza (1997) discussed Roelofs's (1992) theory of word production: "(in this model) the selection of a lexeme is mediated by the selection of the word's grammatical features. Given the centrality of syntactic information $(. .$. in accessing lexemes, I will call this model of the structure of lemmas the 'syntactic mediation' (SM) hypothesis" (Caramazza, 1997, pp. 181-182). However, this reading of the model has not been endorsed by its authors. Roelofs et al. (1998, pp. 224-225) noted that the "model does not assume that selection of form information depends on the selection of gender. Rather, the selection of a lemma node is a prerequisite for
} 
way by the level of activation or availability of these syntactic features. This is because, in these theories, the activation flow between a lexical node and its corresponding syntactic nodes is unidirectional, that is, spreading from the lexical node to syntactic nodes and not vice versa, and that the syntactic nodes are not connected to phoneme nodes. (A schematic representation of this hypothesis about the functional architecture of lexical information processing in spoken word retrieval is displayed in Figure 1.)

This view on the role of lexical syntactic information within the word production system was motivated mainly by empirical evidence pertaining to a specific kind of lexical syntactic information, namely, grammatical gender. Yet there is no a priori reason to consider that conclusions drawn for gender apply to other syntactic properties as well. The different kinds of syntactic properties indeed differ in several aspects. Thus, grammatical gender and category have distinct functions in sentence planning and word formation processes; moreover, gender and category are differently predictable from the word's conceptual features (e.g., Berg, 1992). These differences may have consequences on how they are represented and processed during word retrieval. However, there is little evidence available to date as regards the role of lexical syntactic properties other than gender in word retrieval. The purpose of this study was to seek empirical evidence pertaining to grammatical category information. In particular, inspired by evidence from neuropsychological studies, we entertained the hypothesis that, contrary to information about its gender, information about the grammatical category of a word directly impacts spoken word retrieval.

Evidence pertaining to the role of grammatical gender in word retrieval came, first, from studies of the "tip-of-the-tongue" (TOT) phenomenon (for review, see Brown, 1991). These studies found that, when subjects experience a word in a TOT state, they nevertheless could report its grammatical gender or initial phoneme at better than chance rates (Caramazza and Miozzo, 1997; Miozzo and Caramazza, 1997; Vigliocco et al., 1997). Moreover, and importantly, the subjects could report the initial phoneme of words in TOT states even when they could not report their grammatical gender, which indicates that the retrieval of a word's phonological properties does not strictly depend on the prior successful retrieval of its syntactic properties (e.g., Caramazza and Miozzo, 1997; Miozzo and Caramazza, 1997). Other evidence in support of this view includes response latency data in picture naming experiments using the picture-word interference paradigm. In these experiments, subjects had to name pictures of objects either with a bare noun or a noun phrase (Determiner + Noun or Determiner + Adjective + Noun) while ignoring a distractor word presented simultaneously. The distractor and target word were either gender-congruent (e.g., both feminine) or gender-incongruent (e.g., feminine distractor and masculine target). In the noun phrase production condition, naming latencies were found to be significantly shorter when the distractor and target word were gender-congruent than when they were gender-incongruent (Schriefers, 1993; van Berkum, 1997; La Heij

the selection of gender as well as form information (...). Hence, we fully agree with Caramazza (1997) that speakers can access the form of a word without accessing its grammatical gender."

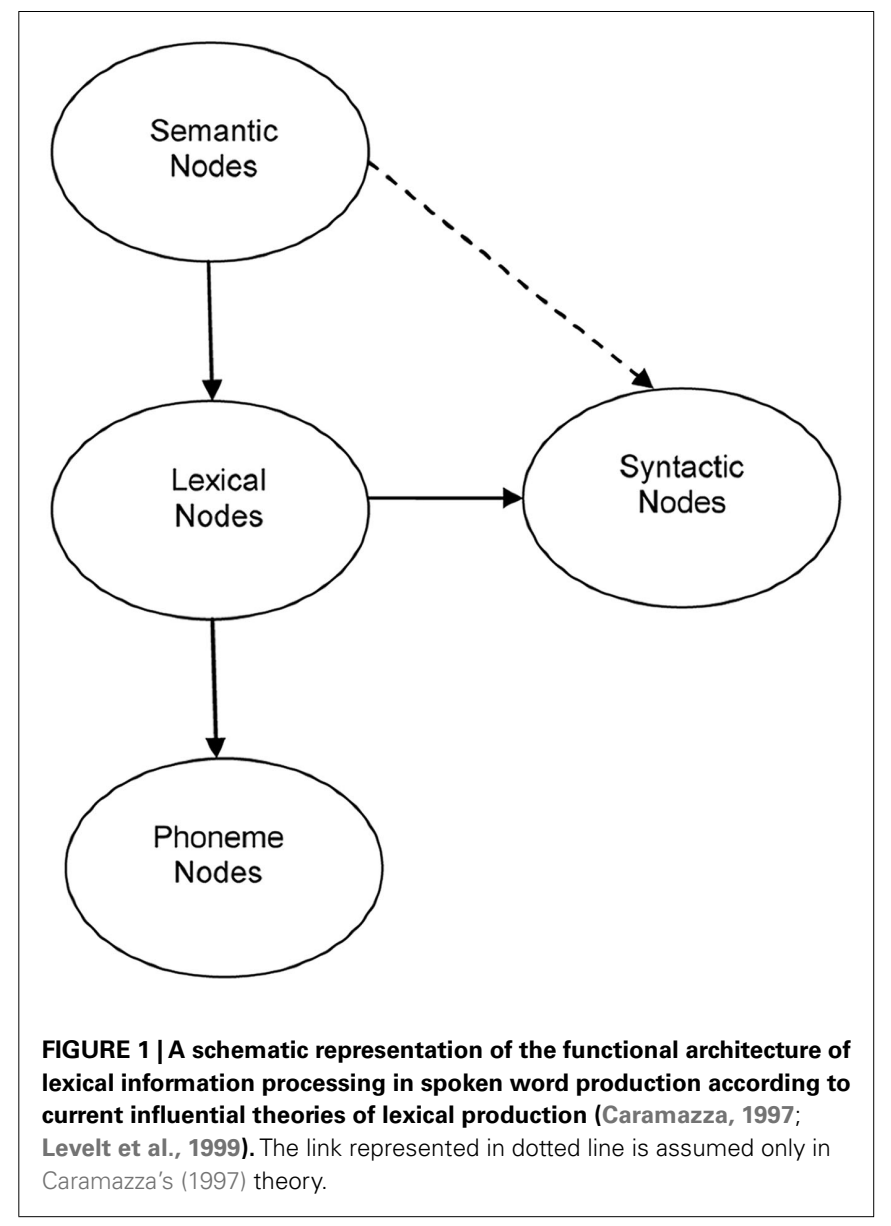

et al., 1998; Schriefers and Teruel, 2000). However, this gendercongruency effect was consistently not found when subjects had to produce a bare noun (Jescheniak, 1994, cited in Levelt et al., 1999; Caramazza et al., 2001; La Heij et al., 1998; Starreveld and La Heij, 2004; for consistent results with a different paradigm, see also Vigliocco et al., 2004; but see Cubelli et al., 2005). On the whole, these results suggest that priming gender information did not facilitate or affect in any way the production of the target noun itself. The facilitation effect observed in the noun phrase condition most likely arises during the selection of the appropriate determiner for the target noun (Caramazza et al., 2001; Schiller and Caramazza, 2003). The retrieval process of the target noun, however, appears insensitive to the relative availability of information about its grammatical gender.

On the other hand, evidence from neuropsychological studies strongly suggested that grammatical category information plays a critical role in word retrieval. The interesting cases are those of brain-damaged patients who are disproportionately impaired in naming words from one grammatical category (verbs or nouns) in the spoken or written modality only (Caramazza and Hillis, 1991; Hillis and Caramazza, 1995a; Rapp and Caramazza, 1998, 2002). For example, in a spoken picture naming task, patient HW (Caramazza and Hillis, 1991) was more impaired with verbs than nouns (he scored $22 \%$ and $56 \%$ correct, respectively) but performed flawlessly for both verbs and nouns in the written version of the same 
task. In contrast, patient EBA (Hillis and Caramazza, 1995a), who was tested with the same material as HW, scored 70\% correct for verbs and $10 \%$ for nouns in spoken picture naming. Because the disproportionate deficit for verbs (HW) or nouns (EBA) was modality-specific, one can rule out that the verb-noun dissociation was due to some semantic features being correlated with the noun-verb distinction. Moreover, these patterns of grammatical category-specific deficit were observed even in tasks requiring the production of a single word, like picture naming, word naming, or naming from a definition. Shelton and Caramazza (1999) proposed to account for these patterns of deficits by assuming that they are the consequence of damage to the connections from modality-specific lexical nodes to a given grammatical category node, which resulted in a grammatical category-specific deficit for that modality. Within this account, grammatical category information is thus viewed as a necessary piece of information to which word retrieval processes need to access in order to successfully retrieve a word's phonological form, even in the context of single word production.

However, the seldom experimental work carried out with healthy participants on the role of grammatical category in word retrieval provided contradictory findings. Pechmann and Zerbst (2002) reported a series of picture naming experiments with the picture-word interference paradigm in which the distractor and the target word were either from the same or a different grammatical category (the target word was always a noun and the distractor was either another noun or a closed-class word or an adverb). In the first experiment, subjects had to name objects depicted in pictures with a bare noun, while in Experiments 2-5, they had first to produce a visually presented sentence fragment (i.e., "Peter sees...") and then name the object with the proper determiner and noun. No significant effect of grammatical category was found in the bare noun production condition (Experiment 1) whereas when the target word had to be produced within the context of a sentence (Experiments 2-5), the naming latencies were significantly longer when the distractor and the target word were from the same grammatical category than when they were from a different category. Such interference effect would reflect competition between the target word and the distractor word for the insertion into the same slot made available by the activated sentence (Pechmann et al., 2004). These findings would suggest that the process of retrieving a word is insensitive to the relative availability of grammatical category information, just like gender information, and that the grammatical category effect observed in the sentence condition reflects the role of such information in sentence planning processes. However, with the same material and procedure, Janssen et al. (2010) did observe a grammatical category effect in the bare noun condition, in addition to the category effect obtained in the sentence condition (Experiment 1). Also, they showed that both effects were no more obtained when the distractors from the same (nouns) and the different (verbs) category from the target noun were controlled in imageability (Experiment 2). They concluded that the putative grammatical category effect observed with the picture-word interference paradigm was an effect of distractor imageability, not of distractor grammatical category and, therefore, that the grammatical category effect observed with that paradigm cannot be used to support the view that grammatical category information affects lexical selection.

Evidence that grammatical category information does influence word production processes was, however, found with another experimental paradigm with healthy participants. Melinger and Koenig (2007) presented to the participants, in a word naming task, orthographically ambiguous but phonologically distinct English nouns and verbs (such as convict, that can be pronounced as the noun CONvict vs. the verb conVICT) preceded by an unambiguous noun or verb. They found that the speakers' naming preference was influenced by the grammatical category of the preceded word, i.e., speakers produced the form of the same grammatical category as the preceded word. This result suggests that grammatical category information is primeable and, moreover, that the activation level of the grammatical category feature can have a direct influence on lexical selection processes, even in single word production. However, as acknowledged by the authors, the paradigm of this study did not allow us to rule out that the priming effect in fact arose during the recognition of the visual stimulus rather than during lexical selection for production.

The experiments reported here aimed at providing additional experimental evidence with healthy participants in support of the hypothesis that grammatical category information, contrary to gender, could impact word retrieval processes.

In the main experiments, we used a blocking paradigm in order to prime lexical syntactic information in the context of a picture (Experiments 1, 4, and 5) or word (Experiment 3) naming. Participants had to produce the same critical words, which were masculine nouns, either within a stimulus list exclusively eliciting masculine nouns (homogeneous condition), within a stimulus list eliciting both masculine and feminine nouns (heterogeneous gender condition), or within a stimulus list eliciting both nouns and verbs (heterogeneous category condition). (For a similar but not identical paradigm used to prime semantic, phonological, and gender information, see Heim et al., 2009.)

We assumed that both gender and grammatical category information is automatically activated in the course of single word production (e.g., Caramazza, 1997; Levelt et al., 1999) and that such information is primeable (Melinger and Koenig, 2007). Hence, the repeated production of words from the same grammatical category or from the same gender would increase the availability of such information during word retrieval processes. Based on previous evidence that the relative availability of gender information does not influence single word retrieval production and that, on the contrary, grammatical category information is used as an additional constraint during single word retrieval processes, we therefore predicted that naming the critical words should be facilitated in the homogeneous condition in comparison with the heterogeneous category condition, whereas no facilitation should be observed in the homogeneous condition in comparison with the heterogeneous gender condition.

\section{EXPERIMENT 1. PRIMING GENDER AND GRAMMATICAL CATEGORY INFORMATION IN PICTURE NAMING}

In this experiment, participants had to name a set of masculine nouns from pictures of objects. Three naming conditions were set by adding filler picture stimuli to this set of pictures. In the 
homogeneous condition (HOM), the filler pictures corresponded to masculine nouns, in the heterogeneous gender (HeGEND) condition, the filler pictures corresponded to feminine nouns, that is, words with a different gender from the critical words, and in the heterogeneous category (HeCAT) condition, the filler stimuli corresponded to verbs, that is, words with a different grammatical category from the critical words.

\section{METHOD \\ Participants}

Thirty-six students from the Psychology undergraduate pool of the Université catholique de Louvain participated in this experiment for course credit. They were all native French-speakers.

\section{Material and design}

Thirty black-and-white drawings of objects from 15 different semantic categories (clothing, containers, food, tools, musical instruments, vehicles, buildings, insects, birds, reptiles, trees, toys, arms, furniture, body parts; see Appendix B) were selected as critical stimuli. These drawings were prepared by a professional illustrator for the purpose of this study. The target word for these critical stimuli was always a masculine noun. The target words had a mean frequency (New et al., 2001) of 21 per million $(S D=8)$, a mean number of letters of $5.8(\mathrm{SD}=1.4)$, and a mean number of phonemes of $4.3(\mathrm{SD}=1.9)$. Three sets of filler pictures were selected: 20 pictures of objects eliciting a masculine noun, 20 pictures of objects eliciting a feminine noun, and 20 pictures of actions eliciting a verb. These three sets of filler words were matched one with the other for cumulative frequency, number of syllables, number of phonemes, and number of letters (all $F s<1$ ). All the filler words were selected in order to be as dissimilar as possible from the critical words in terms of initial phoneme, initial letter, and rime. Moreover, the number of times each initial phoneme, initial letter, and rime present in the critical words appeared in the same position within the filler words was equated across the three sets of fillers. None of the selected items selected was ambiguous as regards its grammatical category.

The naming condition was manipulated as a within-subject and within-item variable. We used a counterbalanced design so that each participant was presented with all naming conditions but had to name each critical picture only once. To achieve this, the 30 critical pictures were distributed across three subsets of 10 critical pictures each and three groups of 12 participants were constituted. In order to set the three naming conditions, three blocks of items were prepared for each group of participants: one block was composed of one subset of 10 critical pictures (masculine nouns) and the 20 filler pictures eliciting a masculine noun (HOM condition); a second block was composed of another subset of 10 critical pictures (masculine nouns) and the 20 filler pictures eliciting a feminine noun (HeGEND condition); the third block was composed of the third subset of 10 critical pictures (masculine nouns) and the 20 filler pictures eliciting a verb (HeCAT condition). The subset of critical pictures that was mixed with the filler pictures eliciting either a masculine noun, a feminine noun, or a verb, was rotated across the three groups of participants. Within a given block, the items were pseudorandomly ordered, with the following constraints: (1) a critical picture was always preceded by at least one filler picture; (2) two successive words did not share their initial phoneme, letter, or rime. Ten additional fillers per condition were selected as "warm-up" items and presented at the beginning of each block. These were 10 pictures eliciting a masculine noun in the HOM condition, five pictures eliciting a masculine noun and five pictures eliciting a feminine noun in the HeGEND condition, and five pictures eliciting a masculine noun and five pictures eliciting a verb in the HeCAT condition. Among these 30 warm-up pictures, 15 pictures (five pictures in each condition, corresponding to masculine nouns) rotated together with the subset of critical pictures across the three groups of participants. In total, each block comprised 40 items: 10 "warm-up" pictures, 10 critical pictures, and 20 filler pictures. Each participant was successively presented with three blocks, one per condition. The order of presentation of the three blocks was rotated across participants. Examples of the pictures used to elicit the production of nouns and verbs are provided in Appendix A. Appendix B provides the lists of items.

\section{Procedure}

The experiment was controlled by the E-Prime software (Schneider et al., 2002). The pictures appeared as a black outline on a white square of $75 \mathrm{~mm} \times 75 \mathrm{~mm}$ in the center of the display. Response latencies were collected with a PST (Psychology Software Tools) serial response box. Each participant was tested individually and was asked to name the pictures as fast and as accurately as possible.

In order to familiarize the participants with the pictures used in the experiment and to reduce the number of alternative naming responses, the material was presented to them before the experiment began. They were first presented all the pictures in a random order together with their modal name (i.e., nouns for the objects and verbs in the infinitive form for actions). Then, they were asked to name the pictures with the modal name and to check their response against the expected name, which was displayed on the screen immediately after their response.

On each experimental trial, a fixation point (a square of $20 \mathrm{~mm} \times 20 \mathrm{~mm}$ ) was presented in the center of the screen for $500 \mathrm{~ms}$; then, the screen was cleared for $100 \mathrm{~ms}$ and the stimulus was displayed until the voice key was triggered. The next trial began after an interval of $1500 \mathrm{~ms}$. Latencies were measured from the onset of the stimulus. Malfunctioning of the voice key and participants' responses were checked by the experimenter. In an attempt to prevent or, at least, reduce potential carry-over effects of conditions, the participants were presented, after each block, a non-verbal distractive task lasting $2 \mathrm{~min}$. In this task, the participants were visually presented with sequences of seven digits in random order and asked to re-order the digits in each sequence in ascending order as fast as possible ${ }^{3}$.

\footnotetext{
${ }^{3}$ We can provide no direct evidence that this 2-min distractive task was effective in preventing carry-over effects between experimental blocks. In a distinct but related area of research, i.e., that of semantic context effects in spoken production, it was found that the effect of semantic homogeneity in picture naming (blocks of items from the same semantic category vs. from different semantic categories) was a relatively long-lasting effect (up to $12 \mathrm{~s}$ ), which was obtained even when the samecategory naming trials were interleaved with different-category trials (Howard et al., 2006) or non-language filler trials (Damian and Als, 2005). However, whether such long-lasting effects could be obtained with the manipulation of the syntactic as opposed to semantic context of naming is unknown. Anyway, to anticipate the results of the present experiments, a significant difference in the average naming
} 


\section{RESULTS AND DISCUSSION}

Participants' errors (semantic or phonological errors, 1.2\% overall) were not analyzed but excluded from the analyses, as well as recording [late responses, responses preceded by a vocalization (euh) or a mouth click] and technical failures (6.8\% of the data). In order to deal with outliers, response latencies that deviated by more than 3.5 SD from their cell mean were also excluded $(0.5 \%$ of the data).

Because a counterbalanced design with identical items across conditions was used, only participant was entered into data analyses as random variable (Raaijmakers et al., 1999; Raaijmakers, 2003) and the group variable was included in the analyses in order to remove variance due to the counterbalancing procedure.

Mean response latencies, SE, and size of the effects with $95 \%$ confidence intervals, as a function of the naming condition, are displayed in Table 1. A significant main effect of condition was obtained $[F(2,66)=3.79, \mathrm{MSE}=1613.31, P<0.03]$. Linear contrasts indicated that the $25-\mathrm{ms}$ advantage of the HOM condition over the HeCAT condition was reliable $[F(1,66)=6.77, P<0.02]$. However, the HOM condition did not significantly differ from the HeGEND condition $(F<1)$.

The results of this experiment confirmed our predictions: naming was faster when the target nouns had to be named within a stimulus list exclusively eliciting nouns than when they had to be named within a stimulus list eliciting both nouns and verbs. On the other hand, naming latency was not influenced by whether the stimulus list elicited only masculine nouns or both masculine and feminine nouns. Our account for the facilitation effect produced by the homogeneous category list is that such a list is likely to increase the availability of grammatical category information, which facilitated the retrieval of the target words because grammatical category information is used during word retrieval. (The issue of whether we are dealing with facilitation in the homogeneous condition or with interference in the heterogeneous condition will be addressed in the General Discussion.)

Three possible alternative accounts for this effect need to be addressed, however. First, since in this experiment, the grammatical distinction between nouns and verbs was confounded with a semantic distinction, that between objects and actions, facilitation in the homogeneous list might be due to the successive naming of items from the same semantic class rather than from the same grammatical category. This is unlikely, however, because there is evidence from experimental studies based on a semantic blocking paradigm, which indicated that picture naming was slower in the context of items belonging to the same semantic category (e.g., Kroll and Stewart, 1994; Damian et al., 2001) or in the context of semantically close items (Vigliocco et al., 2002) in comparison to a heterogeneous semantic context. In our experiment, picture naming was, however, faster in the context composed of items that are supposedly more semantically similar one to the others, that is, in the list exclusively composed of objects, in comparison to

latencies between homogeneous and heterogeneous category blocks will be found, which indicates that potential cross-over effects between homogenous and heterogenous blocks (or the reverse) have been greatly reduced or, at least, were weaker than the category homogeneity effect. Otherwise, no significant effect of category homogeneity should have been observed. the context supposedly composed of semantically dissimilar items (objects and actions). One might object that such discrepancy in the direction of the effect may be due to differences between the specific paradigm used in our experiment and the one used in the experiments showing a semantic interference effect. To address this potential objection, we tested in Experiment 2 whether a semantic interference effect would be found with our specific paradigm as well.

The second possible alternative account for our results is based on the assumption that distinct cognitive processes are involved in object and action naming, which has caused an extra processing cost in the HeCAT condition in comparison to the HOM condition, much like what is observed in experiments requiring task switching across trials (for a review, see Monsell, 2003). It is possible, for example, that the prelexical processes involved in mapping the visual stimulus into a conceptual representation differ between objects and actions; visual recognition of objects indeed involves shape processing while visual recognition of actions requires motion processing, or inferred motion processing when actions are presented as static visual scenes.

Third, the effect of the stimulus list composition might have been caused in fact by the filler pictures in the HOM condition (i.e., object pictures) and in the HeCAT condition (i.e., action pictures) possibly not being equal in processing difficulty or speed. Although the target words corresponding to both kinds of filler pictures were matched on several lexical variables, naming object pictures could be easier and/or faster than naming action pictures because, for instance, visual-to-conceptual mapping would be easier/faster for pictured objects than actions. Inspection of our data reveals that, although both kinds of filler pictures gave rise to a similar amount of participant's errors $(2.1 \%$ and $2.9 \%$ for objects and actions, respectively, a non-significant difference), the filler pictures of objects (masculine nouns) indeed were named, on average, $95 \mathrm{~ms}$ faster than the filler pictures of actions. One can think of two possible mechanisms by which a difference in processing difficulty or speed between both kinds of fillers could have caused faster naming latencies for the critical stimuli in the HOM condition. First, the naming process could have been faster for the critical stimuli in the HOM condition because the preceding trials (the filler pictures) were less difficult to process in that condition than in the HeCAT condition, thereby leaving more resources to perform the task on critical stimuli. Second, slower naming latencies for the filler pictures in the HeCAT compared to the HOM condition might have led participants to set a lower response-time criterion for all the stimuli in the HeCAT condition (Lupker et al., 2003).

In order to address both the switching cost and the resource or response-time criterion accounts, we sought to replicate the findings of Experiment 1 in two further experiments based on the same paradigm and rationale, except that the naming of the filler verbs and nouns was elicited from written word stimuli and the naming of the target nouns was elicited from written words as well (Experiment 3) or from pictures (Experiment 4).

\section{EXPERIMENT 2. PICTURE NAMING WITHIN SEMANTICALLY HOMOGENEOUS vs. HETEROGENEOUS LIST}

The aim of this experiment was to address the semantic account for the facilitation effect of grammatical category homogeneity 
Table 1 | Results of Experiments 1, 3, and 4.

\begin{tabular}{|c|c|c|c|c|c|}
\hline \multirow[t]{2}{*}{ Experiment } & \multicolumn{3}{|c|}{ Naming condition } & \multirow{2}{*}{$\begin{array}{l}\text { Gender homogeneity } \\
\text { effect, (HOM-HeGEND) }\end{array}$} & \multirow{2}{*}{$\begin{array}{l}\text { Category homogeneity } \\
\text { effect, (HOM-HeCAT) }\end{array}$} \\
\hline & $\begin{array}{l}\text { HOM, } \\
\text { homogeneous } \\
\text { gender/category }\end{array}$ & $\begin{array}{l}\text { HeGEND, } \\
\text { heterogeneous } \\
\text { gender }\end{array}$ & $\begin{array}{l}\text { HeCAT, } \\
\text { heterogeneous } \\
\text { category }\end{array}$ & & \\
\hline \multicolumn{6}{|l|}{ EXPERIMENT 1} \\
\hline \multicolumn{6}{|l|}{ EXPERIMENT 3} \\
\hline $\begin{array}{l}\text { Word naming with written } \\
\text { word fillers }\end{array}$ & $500(41)$ & $505(49)$ & $513(49)$ & $5\left(\mathrm{Cl}_{0.95}=-3,13\right)$ & $13\left(\mathrm{Cl}_{0.95}=1,25\right)$ \\
\hline \multicolumn{6}{|l|}{ EXPERIMENT 4} \\
\hline $\begin{array}{l}\text { Picture naming with written } \\
\text { word fillers }\end{array}$ & $601(60)$ & $609(65)$ & $621(65)$ & $8\left(\mathrm{Cl}_{0.95}=-8,24\right)$ & $20\left(\mathrm{Cl}_{0.95}=3,37\right)$ \\
\hline
\end{tabular}

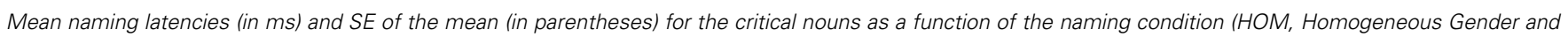

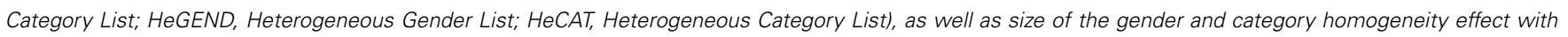
95\% confidence intervals.

obtained in Experiment 1. Indeed, the words in the homogeneous grammatical category condition were all of the same general semantic class (i.e., "objects") while the words in the heterogeneous grammatical category condition were of two distinct semantic classes (i.e., "objects" and "actions"). As we have already mentioned, previous studies (Kroll and Stewart, 1994; Damian et al., 2001) have reported an interference effect when pictures were named within a semantically homogeneous list, which actually weakens the semantic account for the facilitation effect obtained in Experiment 1. However, one could object that the interference effect was observed with a blocking paradigm that differed from the one used in Experiment 1. In Damian et al.'s (2001) study, the participants were presented with 10 semantically homogeneous lists and 10 semantically heterogeneous lists composed of five pictures each and every list had to be named five times, so that in total each picture was named 20 times (blocked-cyclic paradigm). In Kroll and Stewart's (1994) experiment, the participants were presented with 120 pictures representing objects from 12 semantic categories, divided into four lists. In the "categorized" lists, the items were drawn from two to four semantic categories and all the items from a given semantic category were presented in sequence within the list whereas in the "randomized" lists the items from the 12 semantic categories were presented in random order. In contrast, in our experiment, the participants were presented with three lists of 40 pictures, with each list being either homogeneous (HOM and HeGEND conditions) or heterogeneous (HeCAT condition) as regards grammatical category; moreover, each target word had to be named only once. Hence, one cannot rule out that an interference effect in semantically homogenous lists could be found only in an experimental design (number of items and procedure) close to that used by Damian et al. (2001) or by Kroll and Stewart (1994) while, within the design used in our Experiment 1, semantic homogeneity would produce an effect toward the opposite direction - even if it is unclear which specific feature of the designs would be responsible for such discrepancy.

Thus, in this experiment, we tested whether a semantic interference effect would be found with the same design and paradigm as that used in Experiment 1. We used exactly the same number of items and the same procedure as in Experiment 1, except that we manipulated the composition of the lists according to a semantic dimension, which was finer grained than the "objects vs. actions" distinction: 20 animal pictures were selected as critical stimuli to name and they were mixed either with other animal pictures (homogeneous semantic condition) or with pictures from various semantic categories (heterogeneous semantic condition).

\section{METHOD \\ Participants}

Sixteen students from the Psychology undergraduate pool of the Université catholique de Louvain, who were not involved in Experiment 1, participated in this experiment for course credit.

\section{Material and design}

Twenty black-and-white drawings of animals were selected as critical stimuli. The target words had a mean frequency of 13 per million $(\mathrm{SD}=9)$, a mean number of letters of $6.2(\mathrm{SD}=2)$, and a mean number of phonemes of $4.5(\mathrm{SD}=1.8)$. Two sets of filler pictures were selected: 20 pictures of animals and 20 pictures of non-animal objects. All the critical and filler pictures were drawn from Alario and Ferrand (1999). The names of these two sets of pictures were matched for cumulative frequency, number of syllables, number of phonemes, and number of letters (all Fs $<1$ ). All the filler words were selected in order to be as dissimilar as possible from the critical words in terms of initial phoneme, initial letter, and rime. Moreover, the number of times each initial phoneme, initial letter, and rime present in the critical words appeared in the 
same position within the filler words was equated across the two sets of fillers (see Lists of Material in Appendix B).

The naming condition was manipulated as a within-subject and within-item variable. We used a counterbalanced design so that each participant was presented with the two naming conditions but had to name each critical picture only once. To achieve this, the 20 critical animal pictures were distributed across two subsets of 10 critical pictures each and two groups of eight participants were constituted. In order to set the two naming conditions, two blocks of items were prepared for each group of participants: one block was composed of one subset of 10 critical animal pictures and the 20 filler animal pictures (HoSEM condition), the second block was composed of the other subset of 10 critical animal pictures and the 20 filler non-animal pictures (HeSEM condition). The attribution of a critical picture subset to a condition was rotated across the two groups of participants. Within a given block, the items were pseudorandomly ordered, with the following constraints: (1) a critical picture was always preceded by at least one filler picture; (2) two successive words did not share their initial phoneme, letter, or rime. Ten additional fillers per condition were selected as "warm-up" items and presented at the beginning of each block. These were 10 animal pictures in the HoSEM condition and five animal pictures and five non-animal pictures in the HeSEM condition. In total, each block comprised 40 items: 10 "warm-up" pictures, 10 critical pictures, and 20 filler pictures. Among the 20 warm-up pictures, 10 pictures (the five corresponding to animals from each condition) rotated together with the subset of critical pictures across the two groups of participants at the time of the counterbalancing. Each participant was successively presented with the two blocks, one per condition. The order of presentation of the two blocks was rotated across participants.

The procedure was exactly the same as in Experiment 1 (including the presentation of the distractive task between the blocks), except that we used the MEL software to run the experiment.

\section{RESULTS AND DISCUSSION}

Participants' errors (semantic or phonological errors: 5\%) were not analyzed but excluded from the analyses, as well as recording (late responses, responses preceded by a vocalization or a mouth click) and technical failures (5.3\% of the data). In order to deal with outliers, response latencies that deviated by more than $3.5 \mathrm{SD}$ from their cell mean were also excluded ( $0.3 \%$ of the data).

The results indicated that, on average, the naming latencies of the critical stimuli were longer in the HoSEM condition $(662 \mathrm{~ms}$, $\mathrm{SD}=111)$ than in the HeSEM condition $(566 \mathrm{~ms}, \mathrm{SD}=119)$. The 96-ms difference between both conditions was significant [ $F$ (1, $\left.14)=7.28, \mathrm{MSE}=10127.32, P<0.02, \mathrm{CI}_{0.95}=14,178\right]$.

We thus found that, within the same design and procedure as those used in Experiment 1, semantic homogeneity produced an interference effect. This finding made it very unlikely that the facilitation effect observed in the grammatical homogeneous (HOM) condition compared to the grammatical heterogeneous (HeCAT) condition in Experiment 1 had a semantic locus, i.e., that it was due to the grammatical homogeneous list comprising items from the same semantic class (i.e., "objects"). Admittedly, in Experiment 1, our design might have produced a semantic interference effect in the grammatical homogeneous list compared to the grammatical heterogeneous list, because the former possibly included more semantically related items than the latter. Nonetheless, the important result is that the facilitation effect produced by grammatical homogeneity was effective and large enough to outweigh the possible interference effect produced by semantic homogeneity.

\section{EXPERIMENT 3. PRIMING GENDER AND GRAMMATICAL CATEGORY INFORMATION IN WORD NAMING}

Both the switching cost and the resource or response-time criterion accounts for the facilitation effect produced by the HOM condition over the HeCAT condition are related to the processing of the object and action pictures used as fillers possibly being of a different nature, difficulty, or speed. Given that it is probably not feasible to equate both kinds of stimuli according to these variables (see Szekely et al., 2005), these alternative accounts are hard to dismiss in the context of a picture naming task. We therefore sought to replicate the findings of Experiment 1 in a word naming experiment based on the same paradigm and rationale as in Experiment 1. It is reasonable indeed to assume that naming filler verbs and nouns presented as written word stimuli neither relies on distinct cognitive processes nor would give rise to different naming difficulty or speed, if both kinds of stimuli are matched for relevant lexical variables.

We assumed that the spoken production of a word from a written word stimulus relies both on a lexical and a sublexical processing route operating in parallel (Paap and Noel, 1991; Paap et al., 1992) and that word naming shares common word retrieval processes with picture naming at the output stage (e.g., Hillis and Caramazza, 1995b; Lambon Ralph et al., 1999). Hence, we predict that the production of a word in the context of a word naming task is likely to be affected by the availability of grammatical category information just as in the context of a picture naming task.

This expectation finds some motivation in the pattern of performance observed in brain-damaged patients who are selectively impaired in naming words from one grammatical category in the spoken or written modality only. Patient EBA (Hillis and Caramazza, 1995a), for example, showed a selective deficit in the spoken production of nouns in comparison to verbs both in picture and word naming. Importantly, both visual recognition and comprehension of nouns was spared in EBA, which indicates that her deficit in reading nouns aloud was located at the output level. Admittedly, the sublexical processing route for word naming was severely impaired in EBA and it is likely that any lexical effect is more readily detected in such a condition. It is worth noting, however, that the literature on word processing by normal subjects provides ample evidence that reading aloud involves access to semantic or lexical information, even in languages with fully transparent orthography. Thus, many studies have reported semantic effects on word naming latencies, such as effects of the semantic context (Damian et al., 2001), of a semantically related prime (Sperber et al., 1979; Balota and Lorch, 1986; Tabossi and Laghi, 1992), polysemy (Hino and Lupker, 1996; Hino et al., 1998; Lichacz et al., 1999), number of semantic features (Pexman et al., 2002), or concreteness (Strain et al., 1995; Cortese et al., 1997; Shibahara et al., 2003), as well as lexical effects like effects of word frequency (Laudanna et al., 1997; Bates et al., 2001; Raman and Baluch, 2001) 
and age of acquisition (Gerhand and Barry, 1998). On this basis, we thus expected to observe effects of a lexical feature like grammatical category on word naming in normal subjects too.

\section{METHOD \\ Participants}

Thirty-six students from the Psychology undergraduate pool of the Université catholique de Louvain, who were not involved in Experiment 1 or 2, participated in this experiment for course credit.

\section{Material, design, and procedure}

All the items (critical, fillers, and "warm-up" items) selected in this experiment were identical to the items used in Experiment 1, except that written words, instead of pictures, were used as stimuli and had to be named. In addition, we checked that the filler items (the fillers plus the "warm-up" items not involved in the counterbalancing procedure, that is, a total of 25 items by condition) were equated in difficulty, by running an experiment in which only these filler words were presented in separate blocks to 18 (other) participants, who were asked to name them as quickly and as accurately as possible. The results showed no significant difference $(F 1$ and $F 2<1)$ in naming latencies between the filler items (mean $\mathrm{RL}=520 \mathrm{~ms} \mathrm{SD}=47$, mean $\mathrm{RL}=515 \mathrm{~ms} \mathrm{SD}=58$, and mean $\mathrm{RL}=524 \mathrm{~ms} \mathrm{SD}=45$, for masculine nouns, feminine nouns, and verbs, respectively) ${ }^{4}$.

The design and procedure were identical in every respect to those of Experiment 1 (including the presentation of the distractive task after each block), except that, in this case, there was no familiarization phase with the material and that the "+" symbol was used as a fixation point.

\section{RESULTS AND DISCUSSION}

Participants' errors (semantic or phonological errors: $0.7 \%$ ) were not analyzed but excluded from the analyses, as well as recording (late responses, responses preceded by a vocalization or a mouth click) and technical failures ( $2.45 \%$ of the data). Response latencies that deviated by more than $3.5 \mathrm{SD}$ from their cell mean were also excluded $(0.65 \%$ of the data). The results are displayed in Table 1 .

The analyses revealed a significant main effect of condition $[F(2,66)=3.08, \mathrm{MSE}=433.98, P=0.05]$. Linear contrasts indicated that the mean naming latencies of the critical items were significantly shorter in the HOM condition than in the HeCAT condition $[F(1,66)=6.09, P<0.02]$, while the mean latencies of these items did not significantly differ between the HOM and the HeGEND condition $(F=1)$.

We checked that the facilitation effect in the HOM condition was not caused by a difference in naming latencies between the fillers once presented within the specific paradigm and design used in this experiment ${ }^{5}$. We found no significant difference ( $F 1$ and

\footnotetext{
${ }^{4}$ Like in the data analyses of Experiment 1, data points corresponding to a participant's error or a recording or technical failure $(3.2 \%)$ or an outlier $(0.6 \%)$ were removed for the analyses. In addition, the data from one item (ausculter, "auscultating") had to be excluded because of the exceptionally high number of missing data (33\%) for that item. Once this item was removed, the rate of missing data amounted to $3.4 \%$.

${ }^{5}$ Participants' errors and recording or technical failures (3.9\%), and outliers (1.1\%) were excluded from these analyses. In addition, the item ausculter ("auscultating")
}

$F 2<1$ ) in naming latencies between fillers (mean $\mathrm{RL}=516 \mathrm{~ms}$ $\mathrm{SD}=50$, mean $\mathrm{RL}=518 \mathrm{~ms} \mathrm{SD}=50$, and mean $\mathrm{RL}=519 \mathrm{~ms}$ $\mathrm{SD}=49$, for the masculine nouns, feminine nouns, and verbs, respectively $)^{6}$.

Thus, we replicated, in a word naming task, the pattern of results obtained in a picture naming task (Experiment 1). Furthermore, the Cohen's (1988) $D$, an effect size index based on the standardized difference between the means, indicated that the grammatical category effect observed in the word naming task was of a similar magnitude as that observed in the picture naming task ( $D=0.35$ and $D=0.33$, respectively). That we found a similar pattern of results in both tasks undermines an account of the results obtained in the picture naming task solely in terms of a side effect of switching cost, resource differences, or responsetime criterion and supports the interpretation of the facilitation effect found in both picture and word naming as truly originating from the availability of grammatical category information being increased in a homogeneous category list.

\section{EXPERIMENT 4. PRIMING GENDER AND GRAMMATICAL CATEGORY INFORMATION IN PICTURE NAMING WITH WRITTEN WORD FILLERS}

The results of Experiment 3 supported the assumption that even single word naming involves access to grammatical category information. It follows that it should be possible to replicate the grammatical category effect found in Experiments 1 and 3 in an experiment based on the same design and paradigm but in which the filler items are named from written words and the critical items from pictures. Replicating our results in such an experiment would allow us to obtain evidence for the impact of grammatical category information on word retrieval both in a production task which is closer to spontaneous speech production than that of Experiment 3 (i.e., in picture rather than word naming) and in experimental conditions that overcome the potential problems raised by the use of object and action pictures as fillers in Experiment 1. Since the fillers are words, not pictures, and the three kinds of fillers (masculine nouns, feminine nouns, and verbs) would be matched regarding their corresponding response latency (Cf. see Material, Design, and Procedure of the Experiment 3), any account of the results in terms of switching cost, resource, or response-time criterion could be dismissed. Although mixing a word naming and a picture naming task in a single experiment would involve a form

had to be excluded here too because of $33 \%$ missing data. Once this item was removed, the rate of missing data amounted to $4.7 \%$.

${ }^{6}$ One might expect that the naming latencies of the filler verbs would be longer in the context of the experimental, category heterogeneous, list than in the context of the pre-experiment list, which in fact is a category homogenous list (see the Method Section). However, the difference between both these lists does not at all parallel the difference between our experimental conditions (between the category homogeneous and heterogenous experimental lists). Let us remind that we conceived of the category homogeneous list as a priming context. Thus, the critical items in the homogeneous experimental list, on which the mean response latencies were measured, appeared after several "warm-up" and filler items from the same grammatical category have already been named whereas no such category priming occurred in the heterogeneous condition for these same critical items. In contrast, the set of filler verbs were not primed by preceding trials of the same grammatical category in either the category homogenous, pre-experimental list or the category heterogeneous, experimental list. 
of task switching, such mixing is unlikely to hinder the interpretation of the results since it would occur exactly in the same fashion in the three experimental conditions.

Furthermore, in this fourth experiment, we attempted at increasing statistical power by using a sample of 54 participants instead of 36. This was motivated by the results of Experiments 1 and 3 repeatedly showing shorter naming latencies in the HOM in comparison with the HeGEND condition. Although these trends were far from reaching significance $\left(F_{\mathrm{S}}<1\right)$, they could suggest that gender information also could impact spoken word production, albeit to a lesser extent than grammatical category information. A gender priming effect thus could turn out to be reliable with increased statistical power.

\section{METHOD}

\section{Participants}

There was 54 participants in this experiment including 36 students from the Psychology undergraduate pool of the Université catholique de Louvain, and 18 volunteers. None of these participants were involved in Experiments 1, 2, or 3.

\section{Material, design, and procedure}

All the items selected in this experiment were identical to the items used in Experiments 1 and 3. However, in this experiment, pictures served as stimuli for naming critical items and written words served as stimuli to name filler items. The design and procedure were identical in every respect to those of Experiments 1 and 3 (including the presentation of the distractive task after each block), except that, in this case, there was a familiarization phase only with the intended name for the pictures. In addition, the fixation point was the symbol "+" before the display of a picture and a series of six crosses (" $x$ ") before the presentation of a written word.

\section{RESULTS AND DISCUSSION}

Participants' errors (semantic or phonological errors: 1\%) were not analyzed but excluded from the analyses, as well as recording (late responses, responses preceded by a vocalization or a mouth click) and technical failures ( $7.6 \%$ of the data). Response latencies that deviated by more than $3.5 \mathrm{SD}$ from their cell mean were also excluded ( $1 \%$ of the data). The results are displayed in Table 1.

The analyses revealed a significant main effect of condition $[F$ $(2,102)=3.32, \mathrm{MSE}=1619.15, P<0.05]$. Linear contrasts indicated that the mean naming latencies of the critical items were significantly shorter in the HOM than in the HeCAT condition $[F$ $(1,102)=6.56, P<0.02]$ while the mean latencies of these items did not significantly differ between the HOM and the HeGEND conditions $[F(1,102)=1.08, P=0.30]$. We checked that the facilitation effect observed in the HOM condition was not caused by a difference in word naming latencies between the fillers once presented within the specific paradigm and design used in this experiment. We found no significant difference $(F 1$ and $F 2<1)$ in word naming latencies between the different kinds of fillers (mean $\mathrm{RL}=468 \mathrm{~ms} \mathrm{SD}=51$, mean $\mathrm{RL}=467 \mathrm{~ms} \mathrm{SD}=61$, and mean $\mathrm{RL}=469 \mathrm{~ms} \mathrm{SD}=51$, for the masculine nouns, feminine nouns, and verbs, respectively) ${ }^{7}$.

${ }^{7}$ Participants' errors and recording or technical failures (3\%), and outliers (1\%) were excluded from these analyses. In addition, the item ausculter ("auscultating") had
The findings of this experiment thus replicated the pattern of results found in Experiments 1 and 3, within a context where the critical words were named from pictures and the fillers did not differ in nature (all written words), difficulty, or processing speed across the three experimental conditions. Moreover, it is worth noting that the effect of grammatical category found in this experiment $(D=0.32)$ was of a similar magnitude as the effect observed in Experiment $1(D=0.35)$ and Experiment 3 $(D=0.33)$. The priming effect of grammatical category information thus was highly consistent across the three experiments, in spite of their differences in naming conditions and overall naming latencies.

Increasing the number of participants in this experiment still did not allow us to detect a reliable effect of gender homogeneity - but we still found shorter naming latencies in the HOM in comparison with the HeGEND condition, like in Experiments 1 and 3. In order to further increase statistical power, we performed an additional analysis by gathering the data from the three experiments (see Results in Table 1). The ANOVA performed on mean response latencies with Experiment (1, 3, and 4) as between-subject factor and Condition (HOM, HeGEND, $\mathrm{HeCAT}$ ) as within-subject factor yielded a significant main effect of Experiment $[F(2,123)=74.32, P<0.001]$, a significant main effect of Condition $[F(2,246)=8.09, P<0.0005]$, and no significant interaction $(F<1)$. Paired comparisons indicated that the mean naming latencies of the critical items were significantly shorter (by $19 \mathrm{~ms}$ ) in the HOM than in the HeCAT condition [ $F$ $(1,123)=15.03, P<0.0003]$. However, the average 7 -ms difference in response latencies for the critical items between the HOM and the HeGEND condition still did not reach significance [ $F$ (1, 123) $=2.10, P=0.15]$.

\section{INTERIM SUMMARY}

In Experiment 1, we found that picture naming was faster when the target items, which were nouns, had to be named within a stimulus list exclusively eliciting nouns (HOM condition) than when they had to be named within a stimulus list eliciting both nouns and verbs (HeCAT condition). In Experiment 2, we showed that this facilitation effect of grammatical category could not have a semantic origin since semantic similarity among the items of a list resulted in an interference effect. Then, the results of Experiments 3 and 4 allowed us to rule out that the facilitation effect observed in the HOM compared to the HeCAT condition in Experiment 1 was a side effect of the lower processing difficulty of filler object pictures compared to filler action pictures, which could have left the participants more resources available to process the critical object pictures in the HOM compared to the HeCAT condition or led them to set a lower response-time criterion in the HeCAT compared to the HOM condition. Indeed, in Experiments 3 and 4 , we equated the processing difficulty between noun and verb fillers by presenting them as written words instead of pictures of objects and actions. We also addressed the issue of whether the findings from Experiment 1 were possibly due to a switching cost in the HeCAT condition. Were the recognition of the object and

to be excluded here too because of $35 \%$ missing data. Once this item was removed, the rate of missing data amounted to $3.8 \%$. 
action pictures used to elicit nouns and verbs based upon distinct cognitive processes, switching between the processing of an action picture and an object picture in the HeCAT condition might have caused an extra processing cost for naming the critical object pictures. We were able to dismiss this alternative account by showing that, again, naming was faster in the HOM than in the HeCAT condition when the recognition processes were made identical for the stimuli eliciting nouns and verbs, that is, by using written words instead of pictures as both filler and critical stimuli (Experiment 3 ) or by using written words as filler (noun and verb) stimuli and (object) pictures only for the critical stimuli (Experiment 4$)^{8}$.

There remains, however, an ambiguity as to the mechanism underlying the grammatical category effect in these experiments. Our starting assumption underlying our experimental manipulations was that the repeated production of words from the same grammatical category was likely to increase (by repeated priming) the availability of category information during word retrieval. Thus, following this assumption, the "noun" information was made more available in the HOM than in the HeCAT condition because only nouns were produced in the HOM condition. However, in all three Experiments (1,3, and 4), the HeCAT list was made up so that each critical item (a noun) was always preceded by an item of a different grammatical category (a filler verb). Thus, the question arises of whether it was the manipulation of the stimulus list, blocked vs. mixed as regards category, or the nature of the preceding trial, of same vs. different-category, that caused the naming latency differences between the HOM and the HeCAT condition. We empirically addressed this issue in the next experiment.

\section{EXPERIMENT 5. CATEGORY-BLOCKING EFFECT vs. CATEGORY-SWITCHING EFFECT}

The aim of this experiment was to seek direct empirical evidence in support of our interpretation that the shorter naming latencies for the critical items in the HOM compared to the HeCAT condition was due to a blocking effect, that is, an effect originating from the stimulus list being homogeneous vs. heterogeneous as regards grammatical category. (Let us specify here that whether such blocking effect should be viewed as a facilitation effect of the HOM condition or, instead, an interference effect of the HeCAT condition, is a different issue which will be addressed in the General Discussion Section). The alternative to be dismissed is that the longer naming latencies in the HeCAT compared to the HOM

\footnotetext{
${ }^{8}$ Let us note that other possible sources of switching cost, like uncertainty about the task or the word category of the response to provide, were unlikely. Contrary to the typical switching task paradigms (e.g., Altmann, 2007; see for review Monsell, 2003), the participants in Experiment 1 always had to perform the same task - orally name the picture - whatever the picture. Moreover, a given stimulus picture never served to elicit two different responses across trials. A given stimulus picture, say that of a glass, was not used once to elicit the verb drinking and, at another time, to elicit the noun glass. Every stimulus picture in the experiment had to be named with one and only one name from only one word category, a verb or a noun. Finally, as far as the critical items (nouns) are concerned, there was no ambiguity about knowing whether it had to be named as a verb or a noun, since no action was represented in the picture, only an object without any context. Anyway, the results of Experiment 4 ruled out an account in terms of uncertainty as to whether to name the picture as a verb or a noun, since the only kind of pictures presented during this experiment were object pictures to be named as nouns.
}

condition was in fact a category-switching interference effect originating from the critical trials (nouns) always being preceded by a trial eliciting a verb in the HeCAT condition (in addition to being interspersed within a list heterogeneous as regards grammatical category). A category-switching interference effect could be expected if, for instance, it were assumed that noun and verb syntactic nodes were connected by inhibitory links (e.g., Caramazza, 1997). In that case, the activation and selection of the verb node during the retrieval of the name of a verb filler in the HeCAT condition would inhibit the noun node which, on the subsequent critical trial, would then need more activation (more time) to be selected.

In this experiment, we used the paradigm of Experiment 4, that is, the filler nouns and verbs had to be named from written words while the critical nouns had to be named from pictures of objects, by changing the following aspects: (i) we considered only the HOM and HeCAT conditions; (ii) we manipulated the order of appearance of the critical nouns within the HeCAT list so that they had to be named either after naming a verb (category-switching position) or after naming a noun (same-category position). If it were the switching between word categories in the HeCAT condition that produced the effect found in the previous experiments, then we should find (i) that the critical items are named faster in the HOM condition than in the HeCAT condition (because there are no category switches in the HOM condition), and (ii) that the critical items appearing in a category-switching position are named more slowly that the items appearing in a same-category position in the HeCAT condition. No difference in naming latencies between the critical items in a category-switching and a same-category position in the HeCAT condition is expected if the effect found in the previous experiments was a blocking effect.

\section{METHOD \\ Participants}

Thirty-two participants were paid for this experiment. None of them participated in the previous experiments.

\section{Material, design, and procedure}

The critical stimuli were 20 object pictures (masculine nouns) of which most (15) but not all were drawn from the set of critical pictures used in Experiments 1, 3, and 4 (see List of Material in Appendix B). The target words had a mean frequency (New et al., $2001)$ of 16 per million $(S D=9)$, a mean number of letters of 6.1 $(\mathrm{SD}=1.5)$, and a mean number of phonemes of $4.6(\mathrm{SD}=1)$. We also used the same set of filler words as those used in the previous experiments ${ }^{9}$, that is, 25 masculine nouns for setting the HOM condition and 25 verbs for setting the HeCAT condition, to which we added 10 filler pictures of objects (masculine nouns).

The critical pictures were organized in pairs. The two pictures of a pair were presented in immediate succession and at the same position (position 1 or position 2) within the HOM and the HeCAT lists. The picture in position 1 followed a filler word (a noun in the HOM and a verb in the HeCAT list) and the picture in position 2 followed the first picture of the pair. In the HeCAT list,

\footnotetext{
${ }^{9}$ Except that the verb ausculter ("auscultating") was replaced with the verb pondre ("laying") because it generated too many errors.
} 
the picture in position 1 thus appeared in a category-switching position (i.e., after the naming of a verb filler) and the picture in position 2, in a same-category position (i.e., after the naming of a noun). Sometimes, however, a filler object picture was inserted between the two pictures of a pair in order to prevent a predictable alternation between pairs of pictures and filler words. In this experiment, like in Experiment 4, the switching between naming a filler word and a picture thus was unpredictable, but there was no uncertainty about the grammatical category of the word to be named from the pictures, since only pictures of objects, corresponding to the critical noun items, were presented. Finally, we insured that two successive items within a list did not share their initial phoneme, letter, or rime.

The homogeneity of the list (HOM vs. HeCAT) and picture position (position 1 vs. 2, i.e., category-switching vs. samecategory position in the HeCAT list) were manipulated as withinsubject and within-item variables. We used a counterbalanced design so that each participant was presented with both kinds of lists and both position conditions but had to name each critical picture only once. To achieve this, the 20 critical pictures were distributed across two subsets of 10 critical pictures each and two groups of 16 participants were constituted. In order to set the two naming conditions (HOM and HeCAT), two blocks of items were prepared for each group of participants: one block was composed of one subset of 10 critical pictures (masculine nouns) plus one subset of five filler object pictures (masculine nouns) and the 25 filler masculine nouns (HOM condition); the second block was composed of the other subset of 10 critical pictures (masculine nouns), the five other filler object pictures (masculine nouns), and the 25 filler verbs (HeCAT condition). In that way, each of the two blocks was comprised of 40 trials, of which the first 10 trials were filler items (i.e., serving as "warm-up" items). The attribution of a critical and filler picture subset to a condition was rotated across the two groups of participants. Furthermore, the two groups of 16 participants were split in two so that the position in which a target picture appeared into a pair was counterbalanced across the subgroups of participants. Each participant was successively presented with the two blocks and the order of presentation of these blocks was rotated across participants. The procedure was identical in every respect to that used in Experiment 4 (including the presentation of the distractive task after the first block).

\section{RESULTS AND DISCUSSION}

Participants' errors (semantic or phonological errors: 0.5\%) were not analyzed but excluded from the analyses, as well as recording (late responses, responses preceded by a vocalization or a mouth click) and technical failures (6.5\% of the data). No outlier data (response latencies deviating by more than 3.5 SD from their cell mean) had to be excluded. The results are displayed in Table 2.

We performed an ANOVA with homogeneity and position as within-subject variables. (We also included the group factor in order to remove variance due to the counterbalancing procedure, but we will not report its effects). The analyses revealed a significant main effect of category homogeneity $[F(1,28)=6.52, \mathrm{MSE}=1834.64, P<0.02]$, the mean naming latencies of the critical items being significantly shorter in the HOM than in the HeCAT condition. We found no significant effect of position $[F(1,28)=0.04, \mathrm{MSE}=2074.16, P=0.84]$ and the interaction was not significant either $[F(1,28)=0.06$, $\mathrm{MSE}=2019.44, P=0.81]$. Actually, in the HeCAT condition, the difference between the mean naming latencies of the critical items in a category-switching and a same-category position was virtually inexistent $(F=0)$.

Since the homogeneity effect was not modulated by position, these results confirmed that the facilitation effect observed in the HOM compared to the HeCAT condition in Experiments 1, 3, and 4 was independent from any category-switching cost in the HeCAT condition. Therefore, the results obtained in this last experiment allowed us to establish that the effect reported in these experiments were indeed due to a blocking list effect, that is, an effect originating from the stimulus list being homogeneous vs. heterogeneous as regards grammatical category, rather than to a cost produced by the need to name successively two words from a different grammatical category. If it were the switching between word categories that had been responsible for the effect, we would have found a significant difference between the naming latencies of the target items appearing in a category-switching position and the target items appearing in a same-category position within the HeCAT condition, either because the target items in category-switching position were slowed down by the inhibition caused by the naming of the preceding verb, or because the target items in same-category position were speeded up by the priming caused by the naming of the preceding noun. This was not the case. We did not detect any effect of position in the HeCAT condition.

\section{GENERAL DISCUSSION}

The results of this study indicated that the relative availability of information about the grammatical category of a word influences the speed with which that word is retrieved. That we observed such an effect in the context of single word production strongly suggests that grammatical category information impacts word retrieval per se, not merely phrase and sentence syntactic encoding processes. Neither Caramazza's (1997) nor Levelt et al.'s (1999) theory of word retrieval could account for this finding: within these models there is no mechanism allowing lexical syntactic information, once activated or selected, to influence the retrieval of a target word.

In Caramazza's (1997) Independent Network (IN) model of the lexicon, the spoken production of a word starts with the selection of lexical-semantic representations of which activation then propagates toward the lexeme network (of which nodes represent modality-specific lexical items) and the lexical syntactic network (of which nodes represent the syntactic features of words like grammatical category and gender). Thus, grammatical category features receive activation from the semantic network. However, such activation is not sufficient for a syntactic node to reach threshold: selection of the full set of syntactic features of a word requires the prior activation and selection of the lexeme node. Then, activation of the lexeme node results in activation of its associated phonological nodes (i.e., the word phonological form).

Within this theoretical framework, it is possible to account for the priming of grammatical category information but not for how such priming could then facilitate the selection of the lexeme or the phonological nodes. Thus, the priming of category information in 
Table 2 | Results of Experiment 5 (picture naming with written word fillers).

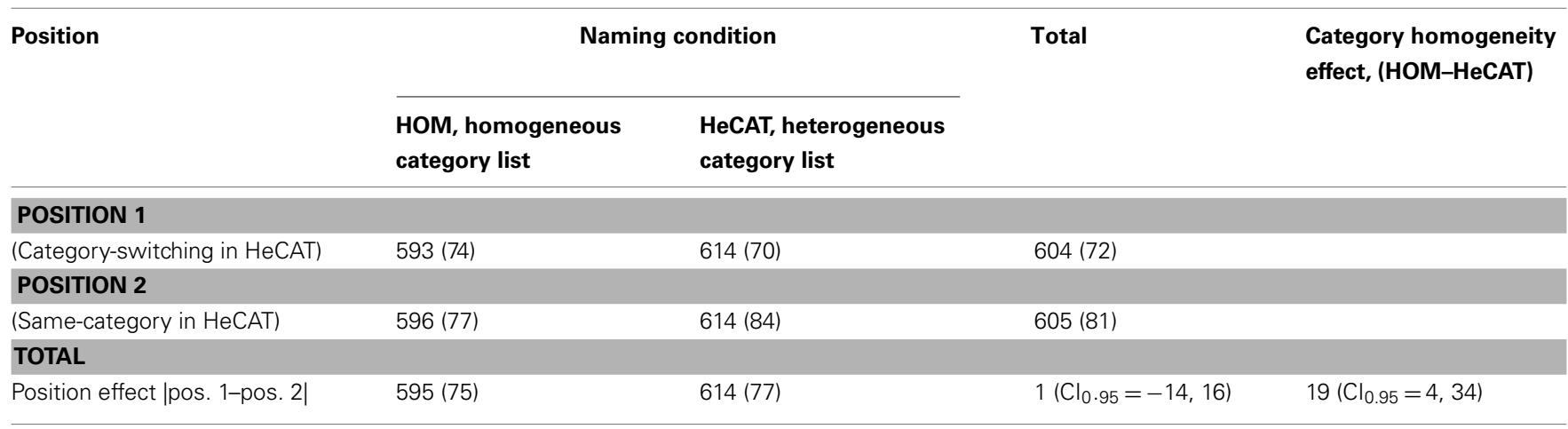

Mean naming latencies (in ms) and SE of the mean (in parentheses) for the critical nouns as a function of the naming condition (HOM, Homogeneous Category List vs. HeCAT, Heterogeneous Category List) and position (Position 1 vs. 2, i.e., category-switching vs. same-category in the HeCat List), as well as size of the category homogeneity and position effect with $95 \%$ confidence intervals.

the context of the blocking paradigm used in our experiments could be described as follows. On presentation of the picture of an object, its semantic representation is activated and that activation then spreads, on the one hand, to the "Noun" node represented in the lexical syntactic network and, on the other hand, to the lexeme node associated with that semantic representation. Then the activated lexeme node spreads its activation to both the "Noun" category node and the phonological nodes to which it is connected. In the homogeneous category naming condition, the "Noun" node is repeatedly activated and selected on each presentation of a picture, which results in enhancing the residual activation of the "Noun" node, which is then more rapidly selected on the subsequent trial. In the heterogeneous category naming condition, the "Noun" category node is comparatively less often activated and selected during the naming task, so that its resting level of activation is lower than in the homogeneous category condition. Further to its repeated activation spreading from semantic and lexeme nodes, a third source of higher activation of the grammatical category node "Noun" in the homogeneous compared to the heterogeneous list could be provided, in a top-down fashion, by the representation of the task (Thompson-Schill and Botvinick, 2006). Even if not specified to them, the participants may notice that only objects (or nouns) have to be named from pictures (or written words). This task-specific requirement for a noun response may act as a prime of the category node "Noun." However, within the IN theory, the level of activation or the selection of the lexeme node does not depend on the level of activation or prior selection of its associated syntactic nodes. Actually, it is even assumed that, in some circumstances, the lexeme node could activate its phonological content even if its syntactic features were not activated or selected. Accordingly, the IN model cannot account for the finding that the level of activation of a grammatical category node impacts the speed of word retrieval.

In Levelt et al.'s (1999) theory of lexical production, the production of a word starts with activation of concept nodes that then spreads to lemma nodes. Upon selection of a lemma node, the syntactic features of the word become available for further grammatical encoding, that is, creating the appropriate syntactic environment for the word. Each lemma node points to one grammatical category node (Verb, Noun, Adjective) and one gender node (Masculine, Feminine, Neuter). Thus, like in the IN model, this theory could predict that the repeated naming of a word from the noun category could enhance the level of activation of the "Noun" category node but it could not explain that the level of activation of this category node then influences the speed of selection of the lemma node and/or, subsequently, the activation and selection of morpheme and phoneme nodes.

How, then, can the impact of grammatical category information on word retrieval be accounted for? First of all, let us specify that the grammatical category node corresponding to a given lexical item should be conceived of as a lexically stored package of information specifying the combinatory rules and the inflectional paradigm of that item (see for a different proposal Marantz, 1997; Barner and Bale, 2002). We propose that it is such information whose level of activation was increased in the homogeneous compared to the heterogeneous category naming condition of our experiments, and that this increased activation facilitated the process of word form retrieval. We can think of two possible, mutually non-exclusive, hypotheses about the level of representation and processing at which such facilitation may arise (see Figure 2). Both of them would require changes in the extant lexical models in relation to assumptions regarding either the structure or the flow of activation between the levels of the network.

The first hypothesis is that the level of activation of a category node could influence the activation and selection of a lexical node. This hypothesis would need to posit bidirectional links between lexical and category nodes. In both the IN and the Levelt et al.'s (1999) models, the connection between lexical and category nodes are unidirectional, i.e., from lexical nodes to a category node. By adding a connection from the category node to lexical nodes, the level of activation of a lexical node could be determined by the activation spreading both from its semantic representation and the grammatical category node to which it is connected. In that way, grammatical category information would act as an additional source of information for the activation and selection of a lexical unit. The assumption that activation may spread from a grammatical category node to lexical nodes is independently motivated by the need to coordinate lexical retrieval and sentence building processes during sentence production (e.g., Stemberger, 1985; 


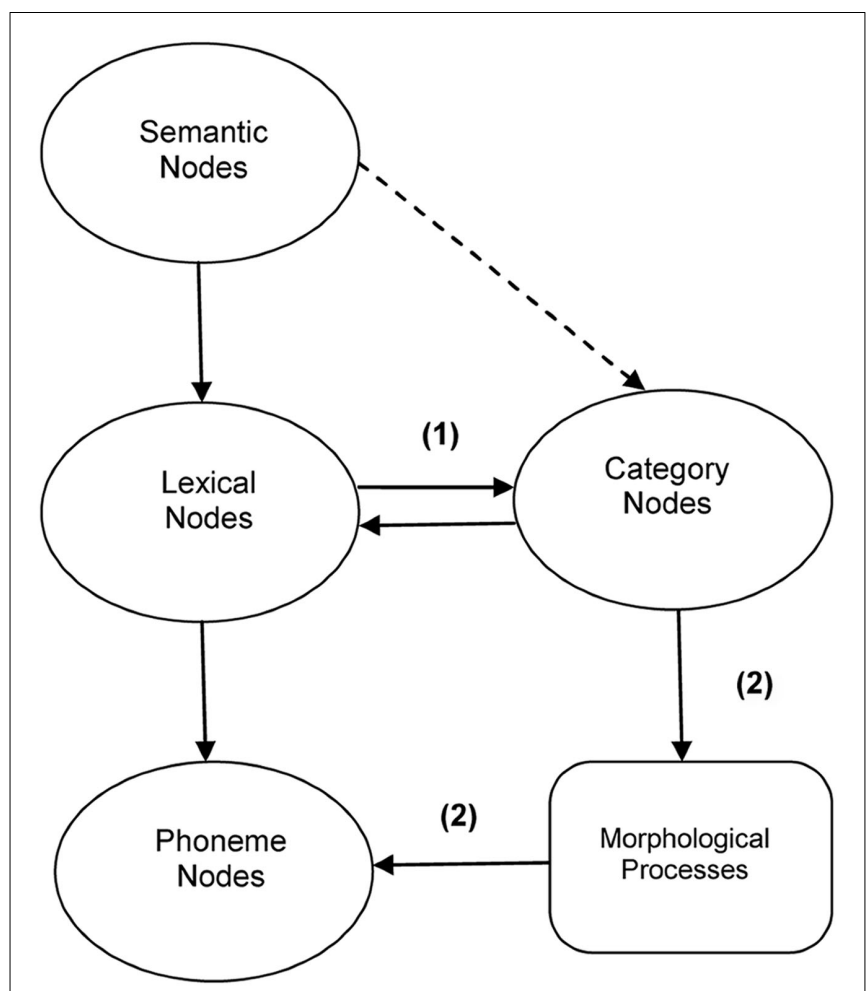

FIGURE 2 |A schematic representation of two hypothetical mechanisms allowing grammatical category information to impact word retrieval processes: (1) Bidirectional links between lexical and grammatical category nodes; (2) Priming of category-specific morphological processes/morphemes.

Dell, 1986; Dell et al., 2008). Within this perspective, grammatical category nodes also receive activation from the syntactic frame specifying a sequence of slots labeled by grammatical category and lexical selection is being guided by the "syntactic-sequential" units defining the grammatical category of the subsequent word to be chosen to fill the sentence frame (Dell et al., 2008). Since by this mechanism, all lexical nodes sharing the same grammatical category (e.g., nouns) would receive part of the activation from a given grammatical category node, this additional source of activation would account for only a small amount of lexical node activation (Goldrick and Rapp, 2002). Nonetheless, this additional activation could be determining for selection in some circumstances like, for instance, when two lexical nodes from distinct grammatical categories have similar levels of activation because of their sharing most of their semantic features (e.g., decide/decision; see Duran and Pillon, 2003).

Behind this proposal lies, implicitly, the idea that the time required to select a lexical node does not depend on the levels of activation of other activated, non-target nodes - that, in other words, lexical selection is not competitive. Because, according to our proposal, all lexical nodes sharing the same grammatical category (e.g., all nouns) would receive activation from the grammatical category node, the level of activation of all these non-target lexical nodes would increase as well as the level of activation of the target node. If the selection of a lexical node were by competition, such mechanism would result in slowing down the selection of the target lexical node, i.e., in an interference effect instead of the facilitation effect described in our proposal. Yet the idea that lexical selection is competitive has long been the received view in the speech production research (e.g., Roelofs, 1992; Levelt et al., 1999). Three sources of evidence has been thought to support this view: (1) the semantic interference effect in the picture-word interference paradigm, in which the visual presentation of a semantically related distractor word slows down the naming of a simultaneously presented picture compared to an unrelated distractor word (e.g., Schriefers et al., 1990); (2) the cumulative semantic interference effect in the continuous picture naming paradigm, in which picture naming latencies increase monotonically as a function of the number of preceding trials from the same semantic category (Howard et al., 2006); and (3) the interference effect of semantic context in the semantic blocking naming paradigm, in which objects are named more slowly in the context of same-category items than in the context of items from various semantic categories (Damian et al., 2001). However, the relevance of all these three sources of evidence for competitive lexical selection has recently been questioned. First, Mahon et al. (2007) reported experimental findings showing that the semantic interference effect in the picture-word interference paradigm occurs at a post-lexical, decision processing level. Second, Oppenheim et al. (2010) showed that competitive lexical selection is not required to explain cumulative semantic interference, which could be modeled as competition arising through learning, and Navarrete et al. (2010) found evidence suggesting that this effect arises prior to lexical selection, through changes to the weights of the connections between semantic and lexical representations. Third, Damian and Als (2005), whose findings showed that the interference effect of semantic context in the semantic blocking paradigm was based on a persistent mechanism, suggested that this effect also could be due to changes in the connections between semantic and lexical representations. To date, there is thus no compelling evidence in support of the notion that lexical selection is a competitive process. Although our findings cannot directly inform this issue, they are more easily explained within the view that lexical selection is not competitive.

Returning to the assumption of bidirectional links between lexical and category nodes, it would be more difficult to integrate within Levelt et al.'s (1999) model because, within this model, it is assumed that sentence construction processes are lexically driven. In other words, it is the lexical node (the lemma) that has been selected with its syntactic nodes that guides the construction of a sentence frame - not the sentence frame that partly drives the selection of a lexical node. We may dispense of bidirectional links and the major changes this hypothesis would imply within the architecture of the lexical (and sentence production) system by simply assuming that a lexical node reaches its selection threshold only when the corresponding grammatical category node is selected. The selection of a category node would then be a prerequisite for the selection of a lexical node. One possible motivation for this constraint is that, at the subsequent processing level, that is, during the phonological encoding of the word, information about its grammatical category is in fact mandatory. The grammatical category of a word indeed determines both the kind of "extrinsic" 
syntactic features (e.g., case and number for nouns, tense, aspect, person, and number for verbs) that have to be assigned to a lexical unit and the inflectional processes that have to be applied to it in order to express these features. Therefore, in languages with inflectional morphology, if one posits that these processes cannot be bypassed, the final phonological shape of a word could not be retrieved or computed if information about its grammatical category is lacking (Shapiro et al., 2000; Shapiro and Caramazza, 2003a).

The second hypothesis about the level at which category information could influence word retrieval is at the phonological processing level. Thus, the increased level of activation of a grammatical category node might facilitate either the selection of the category-specific morphophonological processes or the retrieval of category-specific morphemes. Thus, in our experiments, the facilitation effect observed in the homogeneous condition could reflect the facilitated access to the same inflectional processes (noun inflection) or to the same noun-specific inflectional morpheme (i.e., a zero morpheme, since all the nouns were to be named in the singular form) while, in the heterogeneous context, either noun or verb inflectional process or specific morphemes (i.e., a zero nominal morpheme or the infinitive verbal morpheme) had to be selected depending on the trials. It is presently unclear, however, whether these two notions could be distinguished at the theoretical and empirical levels (for discussion of this issue, see Shapiro and Caramazza, 2003b).

Within the functional architecture of the lexical processing system, grammatical category and gender would thus have a distinct status. At the lexical level of processing, information about the gender of a word could not influence the level of activation of the lexical node corresponding to that word. There would be no connection from gender nodes to lexical nodes, possibly because such connection is not needed to coordinate lexical retrieval with sentence building processes, given that noun selection in the context of a sentence is free of gender constraint. Moreover, at least in languages like French, German, or Dutch, information about the gender of a word could not affect the subsequent level of processing, i.e., the phonological encoding and related morphological processes. In these languages, no inflectional transformation is dependent on gender information; being a masculine or a feminine noun would determine the final form of its determinants and adjectives, but not of the noun itself. However, we would predict that in languages in which gender determines the inflectional transformations that a word can undergo, like, for instance, in Italian (see Cubelli et al., 2005), the priming of gender information could impact the speed of phonological encoding processes and, accordingly, its effect could be reliably detected in a naming experiment using our blocking paradigm.

In other words, according to our proposal, it is not the kind of lexical syntactic features per se that determines how it is represented and processed within the lexical system and how it impacts word retrieval but rather which are its specific functions in sentence and phonological word formation in the language under consideration. Depending on the processing level at which grammatical information indeed impacts word retrieval (i.e., lexical, phonological, or both), we thus expect different effects of grammatical category information on word retrieval across languages and across different classes of words. For instance, if the facilitation of word production by priming grammatical information occurs only at the lexical processing level, similar effects of priming should be observed for nouns, verbs, and adjectives, in both French and English, since a connection from the category nodes to the lexical nodes can be motivated, in both languages, by the need to coordinate the selection of these classes of words with sentence structure building processes. On the contrary, if the facilitation of word production occurred only at the phonological processing level, a priming effect of grammatical category information should be observed for adjectives in French but not in English, since adjectives incur specific inflectional transformations in French but not in English. If the facilitation occurred at both the lexical and the phonological levels, then priming effects could also be observed for adjectives in English albeit to a lesser extent than in French, because word production would benefit from one source of priming instead of two.

Our blocking paradigm, especially with the word naming task, could be employed to test these predictions. Moreover, if it were found that facilitation effects arose at the phonological level of processing, the paradigm could be used to examine whether, at this level, the priming of category facilitates the selection of the category-specific morphophonological processes or the retrieval of category-specific morphemes. If it is the selection of specific morphemes that were facilitated, then facilitation should be observed only when the words to be produced all bear the same inflectional morpheme.

In designing the naming experiments reported here, we made the assumption that the blocking of the grammatical category of the target words in the category homogeneous naming condition should enhance the level of activation of grammatical category information ("Noun") in that condition compared to the heterogeneous condition and then speed up, facilitate, the production of the target nouns compared to the same target nouns mixed with target verbs in the category heterogeneous condition. However, technically, our design does not allow us to know whether we are dealing with facilitation in the homogeneous condition or with inhibition in the heterogeneous condition, since we have no baseline. In the latter case, we can assume, for example, that the production of a verb in the heterogeneous condition led to the selection of the "Verb" category node by inhibition of the "Noun" node, which would then slow down the production of the subsequent nouns because of the need to surmount this inhibition.

Actually, this issue is dependent on whether the selection of lexical syntactic nodes is conceived of as a graded, automatic (discrete), or competitive process, a question that has been debated, so far, in relation to the selection of gender nodes. Thus, some authors (e.g., La Heij et al., 1998; Levelt et al., 1999) viewed the selection process of a gender node as based on graded activation. According to them, the gender-congruency effect in picture-word interference studies (i.e., slower naming latencies when the target and distractor word have the same gender) is a priming effect arising from "repetition-sensitive links between lemmas and the gender nodes" (La Heij et al., 1998, p. 217) or from the gender-congruent distractor "boosting the level of activation of the gender node" of the target word (Levelt et al., 1999, p. 14). Other authors (e.g., Schriefers, 1993) interpreted this effect as an interference effect 
arising from competition between the gender node of the target and the gender node activated by the gender-incongruent distractor word. This interpretation concurs with the assumption made within the IN model (Caramazza, 1997), according to which lexical syntactic feature nodes "have inhibitory links since there are in competition" (Caramazza, 1997, p. 194). Others (Caramazza et al., 2001; Schiller and Caramazza, 2003) argued that the gendercongruency effect is in fact a "determiner-congruency" effect and that lexical syntactic features "automatically become available as part of the selection of a lexical node" (Schiller and Caramazza, 2003, p. 189).

This latter, discrete view of the lexical syntactic feature selection process, which is derived from evidence related to gender selection, cannot explain the grammatical category effect reported here, whether conceived of as a priming or an interference effect. Moreover, the results of Experiment 4 did not favor the interpretation of the grammatical category effect as an interference effect arising from competition between distinct category nodes: the naming of a verb filler at least did not slow down the naming of the subsequent target noun. Thus, the findings of this experiment did not support the view that, when a word is produced, the activation of its grammatical category node inhibit nodes of other categories and, accordingly, all the words of other grammatical categories. More importantly, we believe that assuming competition between grammatical category nodes (as, for instance, in Caramazza, 1997) is not plausible because such a mechanism would be counter-productive in connected speech, where virtually every word produced is from another category than the previous one. If inhibition was created from the category node of the previous

\section{REFERENCES}

Alario, F.-X., and Ferrand, L. (1999). A set of 400 pictures standardized for French: norms for name agreement, image agreement, familiarity visual complexity, image variability, and age of acquisition. Behav. Res. Methods Instrum. Comput. 31, 531-552.

Altmann, E. M. (2007). Comparing switch costs: alternating runs and explicit cuing. J. Exp. Psychol. Learn. Mem. Cogn. 33, 475-483.

Balota, D. A., and Lorch, R. F. (1986). The depth of spreading activation. J. Exp. Psychol. Learn. Mem. Cogn. 12, 336-345.

Barner, D., and Bale, A. (2002). No nouns, no verbs: psycholinguistic argument in favor of lexical underspecification. Lingua 112, 771-791.

Bates, E., Burani, C., D'Amico, S., and Barca, L. (2001). Word reading and picture naming in Italian. Mem. Cognit. 29, 986-999.

Berg, T. (1992). Prelexical and postlexical features in language production. Appl. Psycholinguist. 13, 199-235.

Brown, A. S. (1991). A review of the tipof-the-tongue experience. Psychol. Bull. 109, 204-223.
Caramazza, A. (1997). How many levels of processing are there in lexical access? Cogn. Neuropsychol. 14, 177-208.

Caramazza, A., and Hillis, A. E. (1991). Lexical organization of nouns and verbs in the brain. Nature 349, 788-790.

Caramazza, A., and Miozzo, M. (1997). The relation between syntactic and phonological knowledge in lexical access: evidence from the "tip-ofthe-tongue" phenomenon. Cognition 64, 309-343.

Caramazza, A., Miozzo, M., Costa, A., Schiller, N., and Alario, F. X. (2001). "A cross linguistic investigation of determiner production," in Language, Brain, and Cognitive Development: Essays in Honor of Jacques Mehler, ed. E. Dupoux (Cambridge: MIT Press), 209-226.

Cohen, J. (1988). Statistical Power Analysis for the Behavioral Sciences, 2nd Edn. Hillsdale, NJ: Lawrence Erlbaum Associates.

Cortese, M. J., Simpson, G. B., and Woolsey, S. (1997). Effects of association and imageability on phonological mapping. Psychon. Bull. Rev. 4, 226-231.

Cubelli, R., Lotto, L., Paolieri, D., Girelli, M., and Job, R. (2005). Grammatical

word, this could produce dramatic effects on fluency. Therefore, we believe that it is more plausible to assume that a category node may be primed but not subject to inhibition from other grammatical category nodes, the category node whose level of activation is higher being then selected.

\section{CONCLUSION}

This study provides consistent experimental evidence in support of the hypothesis that information about the grammatical category of a word contributes to the retrieval of that word, even in single word production. Specific hypotheses about the mechanisms by which grammatical category information could influence lexical selection and/or phonological encoding have been proposed. These hypotheses design future directions for empirical studies. Moreover, on their own, the findings of this study do not allow us to make the strong claim that the successful retrieval of a word depends on the retrieval of information about its grammatical category, in particular, because such information is mandatory for the word's morphophonological encoding. However, together with the data from neuropsychological studies showing that brain-damaged patients could be selectively impaired in naming words from one grammatical category, they encourage to entertain this strong hypothesis in further studies.

\section{ACKNOWLEDGMENTS}

We are grateful to Renée Béland for her fruitful comments on this study. This research was partly supported by the FNRS grant no. 1.5.193.01 to Agnesa Pillon.

gender is selected in bare noun production: evidence from the pictureword interference paradigm. J. Mem. Lang. 53, 42-59.

Damian, M. F., and Als, L. C. (2005). Long-lasting semantic context effects in the spoken production of object names. J. Exp. Psychol. Learn. Mem. Cogn. 31, 1372-1384.

Damian, M. F., Vigliocco, G., and Levelt, W. J. M. (2001). Effects of semantic context in the naming of pictures and words. Cognition 81, B77-B86.

Dell, G. S. (1986). A spreadingactivation theory of retrieval in sentence production. Psychol. Rev. 93, 283-321.

Dell, G. S., Oppenheim, G. M., and Kittredge, A. K. (2008). Saying the right word at the right time: syntagmatic and paradigmatic interference in sentence production. Lang. Cogn. Process. 23, 583-608.

Duran, C. P., and Pillon, A. (2003). Independent access to the meaning and the syntax of morphologically complex words: evidence from a case of acquired dyslexia. Brain Lang. 87, 55-56.

Gerhand, S., and Barry, C. (1998). Word frequency effects in oral reading are not merely age-of-acquisition effects in disguise. J. Exp. Psychol. Learn. Mem. Cogn. 24, 267-283.

Goldrick, M., and Rapp, B. (2002). A restricted interaction account (RIA) of spoken word production: the best of both worlds. Aphasiology 16, 20-55.

Heim, S., Eickhoff, S. B., and Friederici, A. D. (2009). Left cytoarchitectonic area 44 supports selection in the mental lexicon during language production. Brain Struct. Funct. 213, 441-456.

Hillis, A. E., and Caramazza, A. (1995a). Representation of grammatical categories of words in the brain. J. Cogn. Neurosci. 7, 396-407.

Hillis, A. E., and Caramazza, A. (1995b). Converging evidence for the interaction of semantic and sublexical phonological information in accessing lexical representations for spoken output. Cogn. Neuropsychol. 12, 187-227.

Hino, Y., and Lupker, S. J. (1996). Effects of polysemy in lexical decision and naming: an alternative to lexical accounts. J. Exp. Psychol. Hum. Percept. Perform. 22, 1331-1356.

Hino, Y., Lupker, S. J., Sears, C. R., and Ogawa, T. (1998). The effects of polysemy for Japanese katakana words. Read. Writ. 10, 395-424. 
Howard, D., Nickels, L., Coltheart, M., and Cole-Virtue, J. (2006). Cumulative semantic inhibition in picture naming: experimental and computational studies. Cognition 100, 464482.

Janssen, N., Melinger, A., Mahon, B. Z., Finkbeiner, M., and Caramazza, A. (2010). The word class effect in the picture-word interference paradigm. Q. J. Exp. Psychol. 63, 1233-1246.

Jescheniak, J. D. (1994). Word Frequency Effects in Speech Production. Doctoral Dissertation, Nijmegen: Nijmegen University.

Kroll, J. F., and Stewart, E. (1994). Category interference in translation and picture naming: evidence for asymmetric connections between bilingual memory representations. J. Mem. Lang. 33, 149-174.

La Heij, W., Mak, P., Sander, J., and Willeboordse, E. (1998). The gendercongruency effect in picture-word tasks. Psychol. Res. 61, 209-219.

Lambon Ralph, M. A., Cipolotti, L., and Patterson, K. (1999). Oral naming and oral reading: do they speak the same language? Cogn. Neuropsychol. 16, 157-169.

Laudanna, A., Cermele, A., and Caramazza, A. (1997). Morpho-lexical representations in naming. Lang. Cogn. Process. 12, 49-66.

Levelt, W. J. M., Roelofs, A., and Meyer, A. S. (1999). A theory of lexical access in speech production. Behav. Brain Sci. 22, 1-38.

Lichacz, F. M., Herdman, C. M., Lefevre, J. A., and Baird, B. (1999). Polysemy effects in word naming. Can. J. Exp. Psychol. 53, 189-193.

Lupker, S. J., Kinoshita, S., Coltheart, M., and Taylor, T. E. (2003). Mixing costs and mixing benefits in naming words, pictures, and sums. J. Mem. Lang. 49, 556-575.

Mahon, B. Z., Costa, A., Peterson, R., Vargas, K. A., and Caramazza, A. (2007). Lexical selection is not by competition: a reinterpretation of semantic interference and facilitation effects in the picture-word interference paradigm. J. Exp. Psychol. Learn. Mem. Cogn. 33, 503-535.

Marantz, A. (1997). "No escape from syntax: don't try morphological analysis in the privacy of your own lexicon," in Proceedings of the 27th Annual Penn Linguistics Colloquium, Philadelphia, Pennsylvania, Working Papers in Linguistics, 4, 201-225.

Melinger, A., and Koenig, J.-P. (2007). Part-of-speech persistence: the influence of part-of-speech information on lexical processes. J. Mem. Lang. 56, 472-489.

Miozzo, M., and Caramazza, A. (1997). Retrieval of lexical-syntactic features in tip-of-the-tongue states. J. Exp. Psychol. Learn. Mem. Cogn. 23, 1410-1423.

Monsell, S. (2003). Task switching. Trends Cogn. Sci. (Regul. Ed.) 7, 134-140.

Navarrete, E., Mahon, B. Z., and Caramazza, A. (2010). The cumulative semantic cost does not reflect lexical selection by competition. Acta Psychol. (Amst.) 134, 279-289.

New, B., Pallier, C., Ferrand, L., and Matos, R. (2001). A lexical database for contemporary French on internet: Lexique. Année Psychologique 101, 447-462.

Oppenheim, G. M., Dell, G. S., and Schwartz, M. F. (2010). The dark side of incremental learning: a model of cumulative semantic interference during lexical access in speech production. Cognition 114, 227-252.

Paap, K. R., and Noel, R. W. (1991). Dual-route models of print to sound: still a good horse race. Psychol. Res. 53, 13-24.

Paap, K. R., Noel, R. W., and Johansen, L. S. (1992). "Dual-route models of print to sound: red herrings and real horses," in Orthography, phonology, morphology, and meaning, eds R. Frost and L. Katz (Amsterdam: North-Holland), 293-318.

Pechmann, T., Garrett, M., and Zerbst, D. (2004). The time course of recovery for grammatical category information during lexical processing for syntactic construction. J. Exp. Psychol. Learn. Mem. Cogn. 30, 723-728.

Pechmann, T., and Zerbst, D. (2002). The activation of word class information during speech production. $J$. Exp. Psychol. Learn. Mem. Cogn. 28, 233-243.

Pexman, P. M., Lupker, S. J., and Hino, Y. (2002). The impact of feedback semantics in visual word recognition: number-of-features effects in lexical decision and naming tasks. Psychon. Bull. Rev. 9, 542-549.

Raaijmakers, J. G. W. (2003). A further look at the "the language-as-fixedeffect fallacy.” Can. J. Exp. Psychol. 57, 141-151.

Raaijmakers, J. G. W., Schrijnemakers, J. M. C., and Gremmen, F. (1999). How to deal with "the language-as-fixedeffect fallacy": common misconceptions and alternative solutions. J. Mem. Lang. 41, 416-426.

Raman, I., and Baluch, B. (2001). Semantic effect as a function of reading skill in word naming of a transparent orthography. Reading Writing 14, 599-614.

Rapp, B., and Caramazza, A. (1998). A case of selective difficulty in writing verbs. Neurocase 4, 127-140.

Rapp, B., and Caramazza, A. (2002). Selective difficulties with spoken nouns and written verbs: a single case study. J. Neurolinguist. 15 , 373-402.

Roelofs, A. (1992). A spreadingactivation theory of lemma retrieval in speaking. Cognition 42, 107-142.

Roelofs, A., Meyer, A. S., and Levelt, W. J. M. (1998). A case for the lemma/lexeme distinction in models of speaking: comment on Caramazza and Miozzo (1997). Cognition 69, 219-230.

Schiller, N. O., and Caramazza, A. (2003). Grammatical feature selection in noun phrase production: evidence from German and Dutch. J. Mem. Lang. 48, 169-194.

Schneider, W., Eschmann, A., and Zuccolotto, A. (2002). E-Prime Reference Guide. Pittsburgh: Psychology Software Tools Inc.

Schriefers, H. (1993). Syntactic processes in the production of noun phrases. J. Exp. Psychol. Learn. Mem. Cogn. 19, 841-850.

Schriefers, H., Meyer, A. S., and Levelt, W. J. M. (1990). Exploring the time course of lexical access in language production: picture-word interference studies. J. Mem. Lang. 29, 86-102.

Schriefers, H., and Teruel, E. (2000). Grammatical gender in noun phrase production: the gender interference effect in German. J. Exp. Psychol. Learn. Mem. Cogn. 26, 1368-1377.

Shapiro, K., and Caramazza, A. (2003a). Grammatical processing of nouns and verbs in left frontal cortex? $\mathrm{Neu}$ ropsychologia 41, 1189-1198.

Shapiro, K., and Caramazza, A. (2003b). The representation of grammatical categories in the brain. Trends Cogn. Sci. (Regul. Ed.) 7, 201-206.

Shapiro, K., Shelton, J., and Caramazza, A. (2000). Grammatical class in lexical production and morphological processing: evidence from a case of fluent aphasia. Cogn. Neuropsychol. 17, 665-682.

Shelton, J., and Caramazza, A. (1999). Deficits in lexical access and semantic processing: implications for models of normal language. Psychon. Bull. Rev. 6, 5-27.

Shibahara, N., Zorzi, M., Hill, M. P., Wydell, T., and Butterworth, B. (2003). Semantic effects in word naming: evidence from English and Japanese Kanji. Q. J. Exp. Psychol. A 56, 263-286.

Sperber, R. D., McCauley, C., Ragain, R. D., and Weil, C. M. (1979). Semantic priming effects on picture and word processing. Mem. Cognit. 7, 339-345.

Starreveld, P. A., and La Heij, W. (2004). Phonological facilitation of grammatical gender retrieval. Lang. Cogn Process. 19, 677-711.
Stemberger, J. P. (1985). “An interactive activation model of language production," in Progress in the Psychology of Language, ed. A. Ellis (London: Erlbaum), 143-186.

Strain, E., Patterson, K., and Seidenberg, M. S. (1995). Semantic effects in single-word naming. J. Exp. Psychol. Learn. Mem. Cogn. 21, 1140-1154.

Szekely, A., D’Amico, S., Devescovi, A., Federmeier, K., Herron, J. D., Iyer, G., Jacobsen, T., Arévalo, A., Vargha, A., and Bates, E. (2005). Timed action and object naming. Cortex 41, 7-25.

Tabossi, P., and Laghi, L. (1992). Semantic priming in the pronunciation of words in two writing systems: Italian and English. Mem. Cognit. 20, 303-313.

Thompson-Schill, S. L., and Botvinick, M. M. (2006). Resolving conflict: a response to Martin and Cheng (2006). Psychon. Bull. Rev. 13, 402-408.

van Berkum, J. J. A. (1997). Syntactic processes in speech production: the retrieval of grammatical gender. Cognition 64, 115-152.

Vigliocco, G., Antonini, T., and Garrett, M. F. (1997). Grammatical gender is on the tip of the Italian tongues. Psychol. Sci. 8, 314-317.

Vigliocco, G., Vinson, D. P., Damian, M. F., and Levelt, W. J. M. (2002). Semantic distance effects on object and action naming. Cognition 85 , B61-B69.

Vigliocco, G., Vinson, D. P., Indefrey, P., Levelt, W. J. M., and Hellwig, F. (2004). Role of grammatical gender and semantics in german word production. J. Exp. Psychol. Learn. Mem. Cogn. 30, 483-497.

Conflict of Interest Statement: The authors declare that the research was conducted in the absence of any commercial or financial relationships that could be construed as a potential conflict of interest.

Received: 14 March 2011; accepted: 31 October 2011; published online: 16 November 2011.

Citation: Duràn CP and Pillon A (2011) The role of grammatical category information in spoken word retrieval. Front. Psychology 2:338. doi: 10.3389/fpsyg.2011.00338

This article was submitted to Frontiers in Language Sciences, a specialty of Frontiers in Psychology.

Copyright $(\odot 2011$ Duràn and Pillon. This is an open-access article subject to a nonexclusive license between the authors and Frontiers Media SA, which permits use, distribution and reproduction in other forums, provided the original authors and source are credited and other Frontiers conditions are complied with. 


\section{APPENDIX}

A. EXAMPLES OF PICTURES OF OBJECTS (ELICITING A NOUN) AND ACTIONS (ELICITING A VERB) USED IN THE PICTURE NAMING

EXPERIMENTS
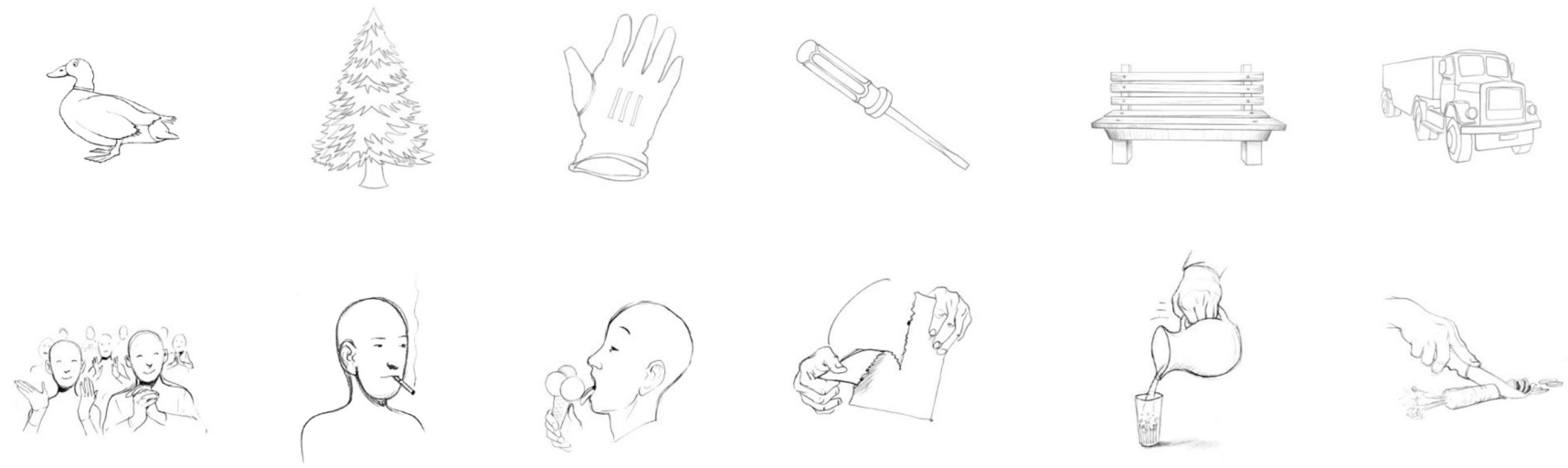


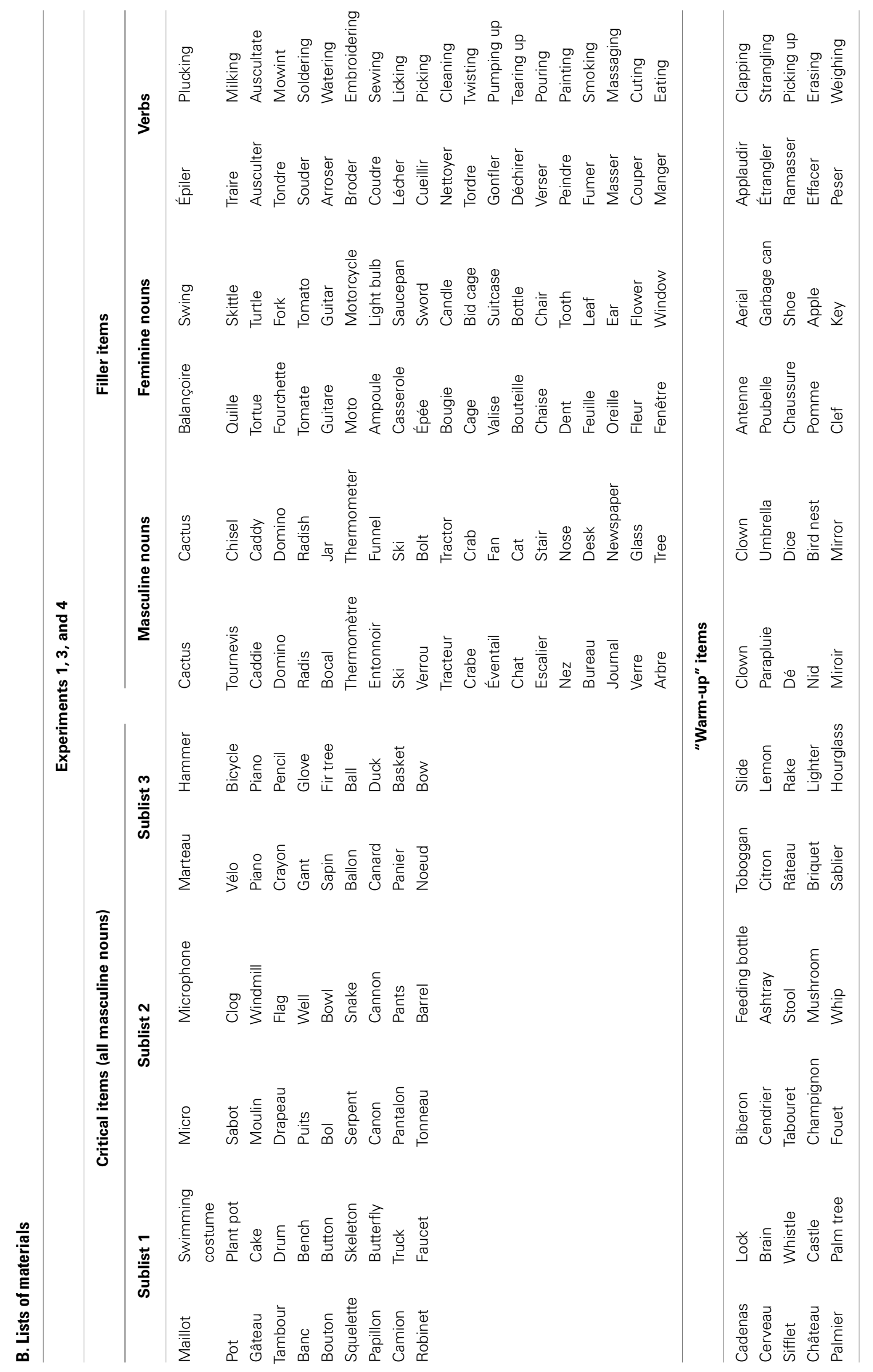




\section{Experiment 2}

\section{Critical items (all animal nouns)}

\begin{tabular}{|c|c|c|c|c|c|c|c|}
\hline \multicolumn{2}{|c|}{ Sublist 1} & \multicolumn{2}{|c|}{ Sublist 2} & \multicolumn{2}{|c|}{ Animal nouns } & \multicolumn{2}{|c|}{ Non-animal nouns } \\
\hline Crocodile & Alligator & Requin & Shark & Koala & Koala & Igloo & Igloo \\
\hline Dauphin & Dolphin & Paon & Peacock & Hippocampe & Sea Horse & Saxophone & Saxophone \\
\hline Tortue & Turtle & Abeille & Bee & Coccinelle & Ladybug & Cadenas & Lock \\
\hline Cygne & Swan & Grenouille & Frog & Pingouin & Penguin & Cactus & Cactus \\
\hline Écureuil & Squirrel & Éléphant & Elephant & Girafe & Giraffe & Arrosoir & Watering can \\
\hline Rhinocéros & Rhinoceros & Coq & Rooster & Gorille & Gorilla & Toupie & Top \\
\hline Aigle & Eagle & Tigre & Tiger & Phoque & Seal & Balançoire & Swing \\
\hline Ours & Bear & Serpent & Snake & Méduse & Jellyfish & Hélicoptère & Helicopter \\
\hline Lion & Lion & Lapin & Rabbit & Scorpion & Scorpion & Cintre & Hanger \\
\hline \multirow[t]{11}{*}{ Mouche } & Fly & Vache & Cow & Baleine & Whale & Fraise & Strawberry \\
\hline & & & & Chenille & Caterpillar & Peigne & Comb \\
\hline & & & & Escargot & Snail & Fourchette & Fork \\
\hline & & & & Araignée & Spider & Ampoule & Light bulb \\
\hline & & & & Cochon & Pig & Marteau & Hammer \\
\hline & & & & Papillon & Butterfly & Crayon & Pencil \\
\hline & & & & Mouton & Sheep & Pipe & Pipe \\
\hline & & & & Souris & Mouse & Bouton & Button \\
\hline & & & & Poisson & Fish & Pantalon & Pants \\
\hline & & & & Chat & Cat & Chaise & Chair \\
\hline & & & & Chien & Dog & Bureau & Desk \\
\hline \multicolumn{8}{|c|}{ "Warm-up" items } \\
\hline Chèvre & Goat & Cerf & Dear & Hippopotame & Hippopotamus & Hamburger & Hamburger \\
\hline Dinosaure & Dinosaur & Kangourou & Kangaroo & Putois & Skunk & Passoire & Colander \\
\hline Oiseau & Bird & Hibou & Owl & Autruche & Ostrich & Lime & Nail File \\
\hline Renard & Fox & Homard & Lobster & Lézard & Lizard & Entonnoir & Funnel \\
\hline Crabe & Crab & Cheval & Horse & Raie & Ray & Robinet & Faucet \\
\hline
\end{tabular}




\begin{tabular}{|c|c|c|c|}
\hline \multicolumn{4}{|c|}{ Experiment 5} \\
\hline \multicolumn{2}{|c|}{ Sublist 1} & \multicolumn{2}{|c|}{ Sublist 2} \\
\hline \multicolumn{4}{|c|}{ CRITICAL ITEMS } \\
\hline Maillot & Swimming costume & Moulin & Windmill \\
\hline Biberon & Feeding bottle & Ballon & Ball \\
\hline Micro & Microphone & Marteau & Hammer \\
\hline Sapin & Fir tree & Sabot & Clog \\
\hline Serpent & Snake & Sifflet & Whistle \\
\hline Cadenas & Lock & Canard & Duck \\
\hline Camion & Truck & Crayon & Pencil \\
\hline Banc & Bench & Bol & Bowl \\
\hline Robinet & Faucet & Champignon & Mushroom \\
\hline Biscuit & Biscuit & Vélo & Bicycle \\
\hline \multicolumn{4}{|c|}{ FILLER PICTURES } \\
\hline Pantalon & Pants & Canon & Cannon \\
\hline Noeud & Bow & Panier & Basket \\
\hline Piano & Piano & Gant & Glove \\
\hline Drapeau & Flag & Papillon & Butterfly \\
\hline Cendrier & Ashtray & Râteau & Rake \\
\hline
\end{tabular}

The filler items were the 25 filler masculine nouns and the 25 filler verbs used in Experiments 1, 3, and 4. 